\title{
LA TRANSICIÓN DESDE LA DELINCUENCIA JUVENIL A LA DELINCUENCIA ADULTA
}

\section{Rolf Loeber, David Farrington y Santiago Redondo}

\section{Introducción}

Los investigadores, los profesionales y el público en general debaten qué lleva a los jóvenes a cometer delitos. Algunos consideran que existen "malas" personas, ya problemáticas desde la infancia, y que muchas de ellas se convierten después en delincuentes persistentes. Otros, por el contrario, argumentan que los delincuentes juveniles son fundamentalmente un producto de su entorno: cuanto peor es su ambiente, peor es su comportamiento a lo largo del tiempo. En 2009 se creó por iniciativa del Instituto Nacional de Justicia del Gobierno de Estados Unidos el Grupo de Estudio sobre la transición desde la delincuencia juvenil a la delincuencia adulta (National Institute of Justice -NIJ- Study Group on Transitions from Juvenile Delinquency to Adult Crime), que ha desarrollado sus trabajos durante un periodo de tres años. Este Grupo de Estudio ha analizado las diferencias entre los delincuentes juveniles que propenden a persistir en la delincuencia entre la adolescencia y la edad adulta temprana y los que, por el contrario, desisten del delito, así como las características de aquellos otros que empiezan a delinquir en la primera edad adulta. Además, en este estudio también se han evaluado las explicaciones teóricas existentes en la actualidad acerca de la persistencia y el desistimiento del delito, y las intervenciones de los sistemas de justicia con los delincuentes que se hallan en el periodo que va desde la adolescencia a la primera edad adulta.

Este artículo presenta las conclusiones generales del trabajo realizado por el Grupo de Estudio NIJ acerca de las transiciones desde la delincuencia juvenil a la delincuencia adulta. La serie completa, que se publicará sucesivamente en esta sección de la REIC, recogerá los resultados e información más recientes de la investigación sobre cuestiones de alta relevancia para la comprensión científica de los fenómenos criminales tales 
como patrones de la carrera delictiva, categorías especiales de los delincuentes graves y violentos, explicaciones del comportamiento delictivo, influencias contextuales sobre la delincuencia, y predicción y evaluación del riesgo y las necesidades de intervención de los delincuentes. Este primer artículo también trata sobre los límites legales existentes en Estados Unidos entre los sistemas de justicia juvenil y el de justicia penal adulta, sobre qué respuesta del sistema de justicia puede resultar más eficaz con los delincuentes juveniles, sobre los métodos de prevención e intervención más adecuados, y sobre algunas recomendaciones en materia de investigación y política criminal. Asimismo, recoge algunos resultados y conclusiones de la investigación española acerca de la prevalencia de las infracciones y delitos juveniles en España (tanto en varones como en mujeres) y sobre los factores de riesgo que se asocian al inicio y a la continuidad o reincidencia delictiva de los jóvenes.

La investigación muestra que los niños que han sido problemáticos se acaban convirtiendo, en un porcentaje pequeño, en delincuentes de carrera. Sin embargo, también se ha hallado evidencia científica acerca de que muchos delincuentes juveniles tienden a dejar de delinquir a finales de la adolescencia y la adultez temprana, y de que esta disminución delictiva está asociada en buena medida a un decremento de la impulsividad de los jóvenes y a un aumento de su capacidad de autocontrol.

Pese a ello, la prevalencia de comportamientos ilícitos es elevada durante la adolescencia y la juventud. Así lo ilustran, por ejemplo, los datos españoles del estudio internacional de autoinforme sobre delincuencia juvenil, obtenidos mediante el Questionnaire for the International Study on Self-Report Delinquency, por el equipo del Centro de Investigación en Criminología de la Universidad de Castilla-La Mancha. El más reciente de sus estudios (Rechea, 2008) evaluó una muestra de 4.152 jóvenes escolarizados, incluyendo adolescentes desde la educación secundaria obligatoria (ESO) hasta segundo curso de Bachillerato y de Formación Profesional, de ambos sexos (49,2\% varones y 50,7\% mujeres) y de edades entre 12 y 17 años. Según este informe, 13 años sería la edad típica autoinformada de comisión de la primera infracción legal, aumentando la frecuencia infractora con la edad. Un 98,8\% de los adolescentes de la muestra refirió haber cometido alguna vez en su vida una conducta ilícita leve, siendo las más comunes bajarse música ilegalmente de Internet (66\% de la muestra), consumir bebidas alcohólicas siendo menores de edad (63\%), haberse emborrachado (41\%), consumir cannabis $(28 \%)$ y participar en peleas $(22 \%)$. Mientras que sólo un $5 \%$ de la 
muestra afirmó haber cometido algún delito violento o contra la propiedad. El porcentaje de chicas infractoras fue inferior al de varones en todos los comportamientos ilícitos y antisociales analizados: participar en peleas, violencia contra las personas, vandalismo, consumo y venta de drogas, y delitos contra la propiedad. Las únicas excepciones a lo anterior fueron el consumo de alcohol y cannabis y el robo en tiendas, infracciones proporcionalmente más frecuentes en las chicas.

A medida que aumenta la gravedad de los delitos lógicamente la prevalencia de jóvenes que participan en ellos es mucho más baja. Un indicador de esto puede ser el número de detenciones de jóvenes. Según datos del Ministerio del Interior de España (recogidos por el Centro Reina Sofía para el Estudio de la Violencia), entre 2002 y 2005 el total de jóvenes detenidos en España (contando nacionales y extranjeros) disminuyó, pasando de 69.409 a 63.880. Es probable que cierta tendencia ligeramente decreciente de la delincuencia juvenil se mantenga en la actualidad. De acuerdo con los datos sobre jóvenes detenidos correspondientes a 2006, el tramo de edad de 18 a 20 años es el que presentó mayor prevalencia de detenciones (con unos 26.434 jóvenes detenidos, lo que correspondió al 58\% del total de detenciones de jóvenes); mientras que el número de jóvenes detenidos en los rangos de edad de 14 a 15 años y de 16 a 17 años, fue 6.835 y 12.281, respectivamente. En el conjunto de detenciones efectuadas anualmente por los cuerpos de seguridad (unas 230.000), los jóvenes representan en torno al 25\%.

Debido a que en la mayoría de los estados de EE.UU. y en muchos países occidentales la transición legal entre la adolescencia y la edad adulta se establece a los 18 años (y en algunos casos a las edades de 16 o 17), constituye un tema importante de debate aquí si verdaderamente los jóvenes tienen pleno control sobre su comportamiento a la edad de 18 años y si su proceso de desarrollo cerebral se ha completado a esa edad. Si así fuera, ¿significaría que a partir de la edad de 18 años el origen de los delitos puede atribuirse, más que a inmadurez personal, a diferencias individuales persistentes y a desventajas familiares, escolares y en el entorno social que los jóvenes experimentan?

Este trabajo de revisión se basa en investigaciones realizadas tanto en América del Norte como en Europa, e incluye las contribuciones de treinta y tres académicos e investigadores. Se centra en el periodo de edad que va desde la adolescencia media a la edad adulta (aproximadamente, desde los 15 a los 29 años). La Tabla 1 resume los cuatro grupos de delincuentes que principalmente nos interesan aquí: menores y adultos cuya actividad delictiva persiste desde la adolescencia hasta la edad adulta temprana (y 
quizás más adelante); adultos que fueron menores delincuentes pero desistieron del delito durante la adolescencia y no continuaron delinquiendo en la edad adulta temprana; adultos que no habían delinquido en la adolescencia sino que se convirtieron en delincuentes al principio de la adultez; y, por último, sujetos no delincuentes que no han delinquido ni en la adolescencia ni en la edad adulta temprana. Los cuatro grupos se han analizado aquí en muestras de población general, prestando atención adicional a grupos de delincuentes especiales como traficantes de drogas, miembros de bandas juveniles, homicidas y delincuentes sexuales.

Tabla 1: La conducta delictiva en las etapas juvenil y adulta temprana

\begin{tabular}{|l|l|l|}
\hline & No delincuente adulto & Delincuente adulto \\
\hline No delincuente juvenil & No delincuente & Inicio adulto en el delito \\
\hline Delincuente juvenil & $\begin{array}{l}\text { Desistencia delictiva antes de } \\
\text { la edad adulta }\end{array}$ & $\begin{array}{l}\text { Persistencia delictiva desde la } \\
\text { juventud a la edad adulta }\end{array}$ \\
\hline
\end{tabular}

\section{Curva de edad del delito y factores de riesgo}

Como ha sido documentando reiteradamente, la relación entre la edad y la delincuencia tiene forma de campana (ver Figura 1): la prevalencia delictiva (es decir, el porcentaje de delincuentes en una población) tiende a aumentar desde finales de la infancia, incrementándose en la adolescencia (entre los 15 y los 19), disminuyendo a principio de la década de los 20 años. Este patrón en forma de campana se conoce como la curva de edad del delito, y es bastante universal en las poblaciones occidentales (Farrington, 1986; Piquero, Farrington, \& Blumstein, 2007).

Sin embargo, las curvas de edad del delito pueden variar en diferentes sentidos. Por ejemplo, la curva de edad de la delincuencia violenta aumenta más tardíamente que la correspondiente a los delitos contra la propiedad (Blokland \& Palmen, en prensa; Piquero, Hawkins, \& Kazemian, 2012). Los estudios también muestran que la curva de la edad del delito asciende antes en las chicas que en los varones (Blokland \& Palmen, en prensa; Farrington, 1986; Elliott, Pampel, \& Huizinga, 2004). La curva también es más ascendente y amplia para los varones jóvenes (especialmente pertenecientes a minorías) que crecen en barrios más desfavorecidos (Fabio, Cohen, \& Loeber, en prensa; Elliott et al., 2004). 
Figura 1: Ejemplo de una curva de edad del delito (Loeber \& Stallings, 2011)

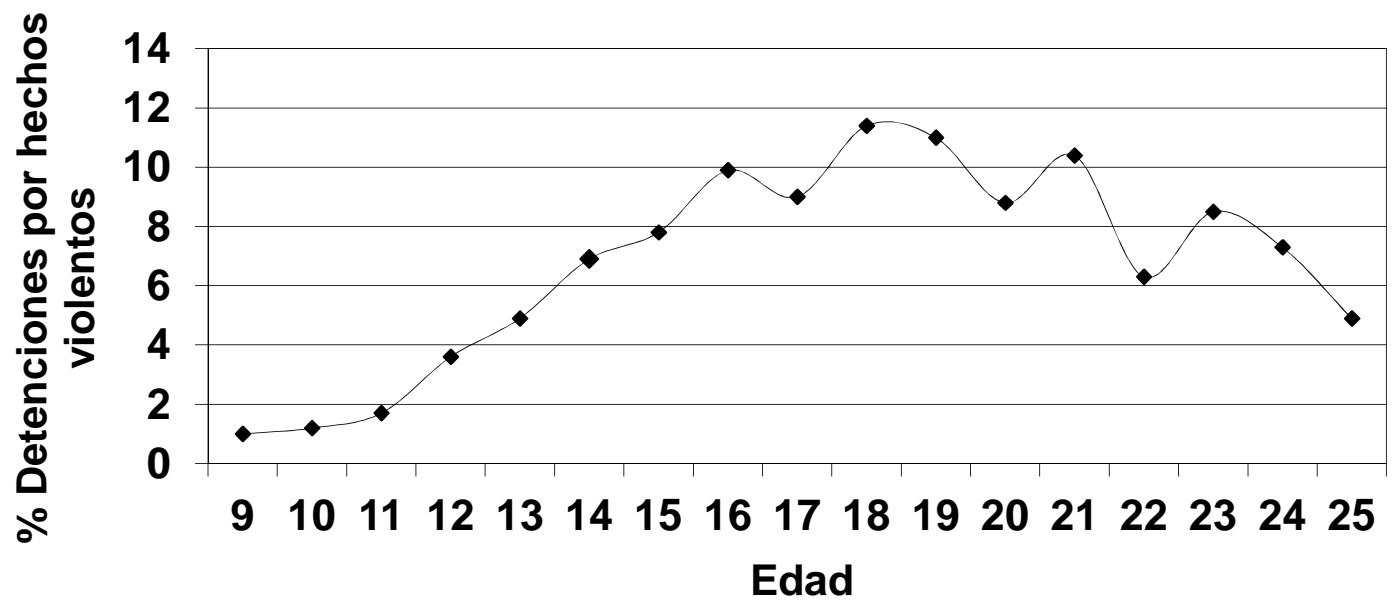

Es importante para nuestra comprensión de la transición de la actividad delictiva entre la adolescencia y la edad adulta prestar atención a la cola derecha de la curva de edad del delito. Un sector derecho de la curva elevado y alargado significa que hay cierta población de jóvenes que o bien no ha superado la delincuencia o bien ha comenzado a delinquir en la edad adulta (véase más abajo). Debe tenerse en cuenta, sin embargo, que la curva típica de edad del delito no informa de la persistencia o desistimiento de los individuos en el delito. Dicha información se deriva exclusivamente de los datos de seguimiento longitudinal, que también resultan claves para conocer la edad típica vs. demorada de inicio en la delincuencia.

Existen otros aspectos de la curva de edad del delito que condicionan las conclusiones que pueden extraerse de ella. Por ejemplo, la delincuencia autoinformada muestra su mayor tasa a una edad más temprana que la cifra oficial de delitos (Piquero et al., 2012). Esto puede reflejar que la delincuencia juvenil a edad temprana (que acaba siendo conocida a través de auto-informes) puede pasar inadvertida a la policía o en todo caso no ser oficialmente perseguida (Piquero et al., 2012). Otra importante consideración metodológica es que la mayoría de curvas de edad basadas en datos oficiales se elaboran a partir de la agregación de datos transversales procedentes de diferentes grupos de edad. Sin embargo, el único modo de estimar la curva de edad sin el sesgo que 
introducen los efectos grupales es el seguimiento de los mismos sujetos en análisis longitudinales (véase, por ejemplo, Loeber, Farrington, Stouthamer-Loeber, \& White, 2008).

En realidad la curva de la edad del delito de un grupo esconde en sí diferentes curvas individuales, incluidos casos cuya delincuencia aumenta constantemente a lo largo de las tres primeras décadas de la vida, y otros cuya delincuencia inicialmente aumenta y luego disminuye. Sin embargo, las investigación muestra que, independientemente de la edad de inicio, la desistencia delictiva se produce generalmente en el sector derecho, en descenso, de la curva de edad, es decir, en la etapa adulta temprana. En otras palabras, la mayoría de los delincuentes deja de cometer delitos, de forma natural, durante la primera edad adulta. Sin embargo, muchas formas graves de delincuencia -incluyendo la delincuencia violenta- se producen en la misma zona en descenso de la curva de edad, es decir durante el periodo general de desistimiento delictivo.

Para la comprensión del inicio y evolución de las carreras delictivas es imprescindible la investigación de los factores de riesgo que se vinculan a estos procesos. Existe mucha investigación internacional a este respecto a la que se hará referencia en próximos artículos de la serie. Por ahora, una mención a algunos trabajos españoles en la materia. Sobral, Romero, Luengo, \& Marzoa, (2000) evaluaron, en una muestra de 3.186 adolescentes escolarizados de 14 a 19 años, los principales factores asociados a la conducta delictiva, que resultaron ser los siguientes: a) en relación al contexto familiar destacaron la falta de apego a los padres, el escaso apoyo recibido, la propia percepción acerca de las malas relaciones con padres y hermanos, y las prácticas educativas de cariz punitivo; b) también se asoció a la conducta antisocial el fracaso escolar; c) la vinculación con iguales delincuentes; y d) variables personales como impulsividad y propensión a la búsqueda de sensaciones. Se hallaron interacciones muy intensas entre variables de personalidad, conducta antisocial y factores contextuales. Específicamente, la búsqueda de sensaciones, la alta impulsividad y la externalidad modularon los efectos de los factores familiares, escolares, grupales y socioeconómicos sobre la conducta antisocial. En la mayor parte de casos amplificando los efectos perniciosos de los factores contextuales.

También se ha realizado en España algún estudio sobre jóvenes delincuentes en la franja de edad 18 a 21 años, que permite conocer algunas de sus características y los correlatos asociados a su actividad delictiva. En concreto, Martín Solbes (2008) efectuó el análisis 
socioeducativo de una muestra de 206 jóvenes (196 hombres y 10 mujeres) internados en las prisiones andaluzas de Sevilla, Algeciras, Málaga y Granada. Su edad promedio era 19 años, y en un 70,5\% eran españoles (en el restante 29,5\% extranjeros de distintas nacionalidades). Se recogió información en cuatro ámbitos: 1) nivel académico y cualificación profesional, 2) relaciones familiares, 3) contactos con la marginalidad, y 4) vida en prisión. Se constató que en general estos jóvenes presentaban un bajo nivel formativo y laboral (un 26\% había completado estudios de Educación Secundaria Obligatoria, sólo el 5\% estudios de Formación Profesional, y apenas un 24,8\% había trabajado más de un año). Un porcentaje elevado (43,7\%) procedía de familias con antecedentes penales y penitenciarios. Más del 30\% estaban casados o vivían en pareja, en algunos casos con hijos. El 88,8\% manifestó que había consumido drogas, siendo la gran mayoría politoxicómanos, especialmente de alcohol, hachís, cocaína, heroína y pastillas (un 78,6\% informó haber participado en programas de desintoxicación). Más de la mitad había cometido delitos contra la propiedad (un 56,3\%), una cuarta parte delitos relacionados con el tráfico de drogas (un 24,3\%), y casi uno de cada cinco, delitos contra las personas (un 19,4\%). Mientras que un 53,4\% afirmaba no haber usado violencia al cometer el delito, el 46,6\% reconocía el empleo de violencia en el mismo.

El 41,7\% de los jóvenes reconoció haber estado ingresado previamente en centros de menores, dato que es ilustrativo de la continuidad de muchas carreras delictivas desde la adolescencia hacia la delincuencia adulta. Es positivo, en dirección a la futura desistencia delictiva de estos sujetos, que el 61,2\% admitiera su propia responsabilidad y culpabilidad en el delito, señalando eso sí (lo cual no deja también de ser realista) hacia otros factores corresponsables, tales como el barrio en que vivían, los amigos y, en general, las personas con las que se relacionaban en la calle (más del 50\% de los sujetos manifestaba que había cometido su primer delito animado a ello por los amigos). Así, un aspecto relevante de este análisis es la constatación de la continuidad entre las actividades infractoras adolescentes y las conductas delictivas juveniles. Sin embargo, el conocimiento de la posible continuidad de las carreras delictivas desde la adolescencia a la juventud choca en España con el obstáculo de la separación informativa entre los sistemas de justicia juvenil y penitenciario, algo que convendría resolver en el futuro.

\section{Inicio, persistencia y desistencia delictiva}




\subsection{Continuidad y desistimiento}

Las cuestiones clave abordadas en este artículo sobre carreras criminales son las siguientes: ¿En qué grado son habituales la persistencia y el desistimiento de la conducta delictiva en el periodo que va desde la adolescencia a la adultez temprana, y con qué frecuencia el inicio delictivo tiene lugar durante la edad adulta? En general las investigaciones muestran una fuerte continuidad de la actividad delictiva desde la infancia y adolescencia hasta las edades juvenil y adulta, continuidad que se asocia a distintos factores de riesgo. Por ejemplo, Luengo, Carrillo de la Peña, Otero, \& Romero (1994) evaluaron una muestra de 1.226 adolescentes (583 varones y 643 chicas) de 12 a 18 años, con el objetivo de analizar longitudinalmente la relación entre impulsividad y estabilidad o cambio de la conducta antisocial. Para esta investigación se emplearon diversos cuestionarios, entre ellos el Eysenck Personality Questionnaire (EPQ), la Escala de Personalidad Antisocial (diseñada por el propio equipo de investigación), la Eysenck Impulsivity Scale y la Barrat Impulsivity Scale (BIS-10). En primer lugar, los análisis correlacionales confirmaron una estrecha asociación entre impulsividad y conducta antisocial adolescente, especialmente en las dimensiones conductuales "ruptura de normas", "agresión” y "vandalismo". En segundo término se comprobó la gravedad y estabilidad de la conducta antisocial aumentaba en proporción al nivel de impulsividad.

Romero (2006) estudió una muestra de 91 niños con el objetivo de examinar qué factores predecían al inicio e intensificación de las conductas problemáticas. Para ello los niños fueron contactados en dos momentos distintos: 1) cuando tenían 6-10 años fueron ampliamente evaluados en relación con su familia y sus características neuroendocrinas y de personalidad (tiempo 1); y 2) a las edades de 10-14 años se midió su comportamiento mediante diversos instrumentos psicológicos estandarizados (tiempo 2). Las correlaciones mostraron que la información facilitada por los padres (medida en el tiempo 1) fue la que mejor predijo los problemas de conducta en el tiempo 2. En relación con las variables familiares, los mejores predictores de riesgo fueron los factores desacuerdo paterno sobre la educación de los niños, coerción verbal y coerción física por parte de los padres, e indiferencia paterna. En relación con los factores neuroendocrinos de los sujetos, las variables que mostraron mayor asociación con problemas de conducta fueron la dificultad para una atención selectiva y sostenida y algunas medidas de función ejecutiva tales como las dificultades de planificación, 
contextualización de objetivos y autorregulación. De las variables de personalidad, los mejores predictores fueron el déficit en empatía, la alta impulsividad y algunos indicadores de psicopatía. Se obtuvieron patrones similares de correlaciones con los problemas de conducta informados por los maestros, y con los criterios de conducta definidos en el trastorno antisocial de la personalidad.

Un análisis de regresión ponderó la capacidad de diferentes clusters de factores predictivos para explicar la variabilidad de las conductas antisociales. A este respecto, las variables de personalidad mostraron el coeficiente de determinación más elevado $(\mathrm{R} 2=.48)$, seguidas de las variables neurocognitivas $(\mathrm{R} 2=.20)$, y de las variables familiares $(\mathrm{R} 2=.17)$. Como en otros análisis longitudinales, se hallo una alta estabilidad de los problemas de conducta entre el tiempo 1 y el tiempo 2 (con correlaciones de $.73 \mathrm{y}$ .69, respectivamente, para las evaluaciones de padres y maestros). Los mejores predictores de estabilidad antisocial fueron las variables coerción verbal paterna, alta impulsividad, susceptibilidad al aburrimiento, déficit para la atención selectiva y sostenida, bajo cociente intelectual, y otras medidas de déficits en atención e inteligencia. Romero (2006) concluye que sus resultados son consistentes con la investigación previa y algunos modelos teóricos como el de Moffit (1993) que consideran que la escalada en problemas de conducta es el resultado de la influencia combinada de dificultades temperamentales (lo que se hallaría conectado con disfunciones neuropsicológicas) y de inefectivas prácticas de crianza paterna.

Pese a que diversas investigaciones, como las anteriormente comentadas, han evidenciado una tendencia a la estabilidad de la conducta antisocial, los estudios también documentan grandes variaciones en la persistencia delictiva, la cual puede oscilar en función de las fuentes de datos sobre el delito que se consideren (cifras oficiales o delincuencia auto-informada) y según cuál sea la población de jóvenes estudiada (si se trata de población general o específicamente delictiva). Presentan mayor continuidad delictiva entre la edad juvenil y la primera edad adulta aquellos jóvenes que empiezan a delinquir más tempranamente, los delincuentes juveniles crónicos, y los que han cometido hechos más violentos. Le Blanc \& Fréchette (1989) hallaron que "entre el $30 \%$ y el $60 \%$ de los adolescentes detenidos por la policía o condenados por un tribunal acababan teniendo algún expediente penal en la edad adulta” (p. 83). En paralelo observaron que la actividad delictiva adolescente no era una fidedigna "semilla de 
estabilidad" delictiva adulta, sino que diversos factores debían ser considerados a este respecto (p. 85).

Hay grandes diferencias individuales en la probabilidad de que un delincuente juvenil devenga delincuente reincidente en la edad adulta. En general, los jóvenes que se inician en la actividad delictiva con antelación a la edad de 12 años, en comparación con quienes comienzan más tardíamente, tienen mayor probabilidad de convertirse en delincuentes juveniles que persistirán en el delito en la adultez temprana (Loeber \& Farrington, 2001). Utilizando buenos datos de auto-informe y cifras oficiales correspondientes al Estudio de la juventud de Pittsburgh (Pittsburgh Youth Study, PYS), Stouthamer-Loeber (2010) encontró que entre el 52\% y el 57\% de los menores delincuentes continuaron delinquiendo en la edad adulta temprana (edades 20-25), pero que esta tasa delictiva se redujo en dos tercios, al porcentaje de entre el 16\% y el 19\%, a lo largo de los siguientes cinco años.

No todas las categorías delictivas presentan los mismos años de persistencia o continuidad delictiva. Los hallazgos realizados por Rosenfeld y sus colegas (2012) muestran que el tráfico de drogas y la posesión ilícita de armas mostraban la mayor duración y persistencia en la edad adulta, mientras que la pertenencia a pandillas delictivas tenía una menor continuidad. Sin embargo, entre los delitos de drogas, el consumo de marihuana tuvo una permanencia entre dos y cuatro veces más prolongada que delitos como el robo y la violencia graves. Estos resultados son coincidentes con la conclusión de Le Blanc \& Frechette (1989) acerca de que la actividad delictiva asociada al tráfico de drogas tendría una edad de finalización más tardía (21,6 años). Rosenfeld y sus colegas (2012) también encontraron que los delitos menores (como vandalismo, hurto y robo de vehículos de motor) tienden a cesar antes de los 18 años. Estos datos sugieren que el conocimiento sobre la asociación entre características del delito y duración residual de la carrera criminal puede ser relevante para la toma de decisiones de la justicia acerca del tipo y duración de las penas, el tratamiento, la libertad condicional, y el encarcelamiento.

Otra cuestión relevante es cómo la frecuencia de los delitos cometidos por delincuentes activos varía por rangos de edad. Piquero et al. (2012) concluyeron que la frecuencia anual de delitos es mayor para las formas no violentas de la delincuencia que para los delitos violentos. La frecuencia delictiva suele alcanzar su mayor cota a las edades de 17 a 19 años, y esta elevada frecuencia se mantiene estable sólo en un grupo pequeño de 
delincuentes (debido a que la mayoría de carreras delictivas tiene una duración menor, de entre 5 y 10 años). Sin embargo, Blokland \& Palmen (en prensa) encontraron que la frecuencia media de delitos permanecía estable en el tiempo, tal y como anteriormente habían argumentado Blumstein et al. (1986).

Múltiples estudios coinciden en que una proporción sustancial de delincuentes juveniles, de alrededor del 40-60\%, desiste del delito al principio de la edad adulta. El periodo entre la adolescencia y la primera edad adulta se caracteriza por un aumento de la gravedad delictiva (incluidos los delitos violentos) para el caso de una minoría de delincuentes, e inversamente por una disminución de la gravedad de los delitos cometidos por otros sujetos. Para quienes continúan delinquiendo la transición entre la adolescencia y la edad adulta denota un periodo de creciente gravedad de los delitos y de aumento de la violencia letal (véanse, por ejemplo, Farrington, 2003; Le Blanc \& Fréchette, 1989; Loeber \& Farrington, 1998). La expresión "delitos graves" hace referencia aquí a agresiones y homicidios, tráfico de drogas, y posesión de armas (Loeber et al., 2008). Dado que la mayor parte de la violencia delictiva suele dirigirse a víctimas de edad semejante a la del agresor, no es de extrañar que el periodo de 16 a 24 años sea también una etapa de mayor riesgo de victimización violenta (por ejemplo, Kershaw, Nicholas, \& Walker, 2008; Truman \& Rand, 2010). Los procesos de agravamiento delictivo para el caso de algunos varones jóvenes, y de desaceleración delictiva en los demás, no suelen completarse antes de los 18 años sino que se extienden hasta la edad adulta temprana.

\subsection{Reincidencia de los jóvenes}

Para el conocimiento de las tasas de persistencia en el delito, de la topografía de los delitos y de los factores que se asocian a ellos resultan relevantes diversos estudios españoles sobre reincidencia delictiva de los jóvenes. Por ejemplo, Bravo, Sierra, \& del Valle (2007) analizaron una muestra de 382 jóvenes (327 varones y 55 chicas) que habían cumplido alguna medida judicial entre 2001 y 2003 en el Principado de Asturias. La edad media de apertura del expediente judicial por delito fue de 16,7 años para los varones, y ligeramente superior, de 17 años, para las chicas. Los delitos más frecuentes cometidos por los varones fueron robos con fuerza y, en segundo término, lesiones. En cambio, a pesar de tener una tasa mucho más baja que en los varones, los delitos más frecuentes en las chicas fueron robos con intimidación y lesiones. La tasa de 
reincidencia global de la muestra fue del $29,6 \%$ para un período de seguimiento de entre 1 y 4 años.

Capdevila, Ferrer, \& Luque (2006) analizaron en Cataluña la reincidencia delictiva, durante un periodo de seguimiento de 2 a 3 años, de una amplia muestra de 2.903 jóvenes (2.534 varones y 369 chicas) que habían cumplido diferentes medidas en justicia juvenil. El 82\% de los sujetos de la muestra era de origen español. Además se tuvieron en cuenta las diferentes medidas judiciales cumplidas por los menores (mediación y reparación, asesoramiento técnico, medidas cautelares, otras medidas en medio abierto, prestaciones en beneficio a la comunidad, libertad vigilada e internamiento). Los datos más relevantes de este estudio fueron los siguientes: 1) la edad media de apertura del expediente judicial fue de 16,05 años; 2) el 65,8\% de la muestra había cometido un delito contra la propiedad, un 17,3\% un delito de lesiones, un $4,3 \%$ contra la seguridad colectiva, y un $0,7 \%$ contra la libertad sexual; 3) la tasa general de reincidencia fue de $22,73 \%$. También se analizaron qué variables constituían predictores de riesgo para la reincidencia de los menores, destacando los siguientes: los varones reincidieron en mayor grado (un 25,2\%) que las chicas $(12,7 \%$ ), dato que resulta acorde con el conjunto de la investigación en este campo; aunque los extranjeros presentaban mayor número de factores de riesgo, la condición de extranjería no se asoció a la magnitud de la reincidencia; se vinculó a la mayor reincidencia el consumo de drogas o el padecimiento de algún trastorno mental; los reincidentes mostraron más factores sociofamiliares desfavorables (más rupturas de vínculos con sus padres, mayor proporción de malos tratos, experiencias educativas incoherentes y poco efectivas, etcétera); también se asoció a la mayor reincidencia no tener domicilio fijo ni convivir con la familia de origen, no estar matriculado en la escuela ni contar con formación escolar o trabajo, y estar vinculado a una pareja disocial o a amigos delincuentes; los jóvenes reincidentes tenían más antecedentes delictivos y habían cometido delitos más violentos; los reincidentes eran en general más jóvenes que los no reincidentes cuando finalizaron el cumplimiento de la medida impuesta; por último, se observó que los jóvenes a los que se había aplicado una medida de internamiento (lo que solía corresponder con perfiles delictivos más duros) presentaban mayor probabilidad de reincidir tanto en el sistema de justicia juvenil como posteriormente en el de adultos.

San Juan, Ocáriz, \& de la Cuesta (2007, 2009) efectuaron una evaluación de las medidas en medio abierto del plan de justicia juvenil de la comunidad autónoma del 
País Vasco, para el periodo 2003-2004, incluyendo el análisis de la reincidencia delictiva y los factores asociados a ella. La tasa global de reincidencia para el conjunto de la muestra, para un periodo de seguimiento de 5 años, fue del 21,5\%. Sin embargo, en un análisis más pormenorizado, se observó que aquellos jóvenes que habían cumplido medidas judiciales en medio abierto reincidieron en un 40,4\%, mientras quienes habían cumplido medidas de internamiento en régimen cerrado reincidieron en un 59\%. En este tipo de análisis comparativo siempre debe tenerse presente, y así lo señalan los propios autores de este estudio (véase también Redondo, Funes y Luque, 1994), que la mayor reincidencia del grupo que había sido sentenciado a internamiento puede ser prioritariamente debida, no al tipo de medida que les fue impuesta, sino al hecho sustantivo de su mayor riesgo delictivo (evidenciado en las infracciones más graves que habrían cometido con anterioridad). Sin embargo, San Juan et al. (2007) no hallaron en este caso una relación estadística significativa entre la gravedad de los primeros delitos cometidos por los jóvenes y su reincidencia posterior. Alternativamente a ello, encontraron que los dos principales predictores de la reincidencia delictiva de esta muestra fueron el fracaso escolar de los jóvenes y el tipo de medida judicial (internamiento vs. medio abierto) que les había sido inicialmente aplicada. Los jóvenes reincidentes se caracterizaron por ser varones, de nacionalidad española, procedentes de familias numerosas con dificultades económicas y de familias desestructuradas, y con menores vínculos afectivos. Asimismo, a diferencia de los jóvenes no reincidentes, presentaban mayor consumo de tóxicos, mantenían relaciones sociales de riesgo y tenían mayor probabilidad de padecer trastornos mentales, o mostrar hiperactividad e impulsividad.

En un estudio específico sobre la aplicación de la medida de libertad vigilada a infractores juveniles de las provincias de Zaragoza, Málaga y Toledo, Bernuz, Fernández, \& Pérez (2009a) constataron que la "libertad vigilada" puede ser un buen instrumento de intervención con menores infractores, permitiendo conjugar objetivos de educación y de control. En concreto estas autoras (Bernuz, Fernández, \& Pérez, 2009b) evaluaron 60 expedientes de menores que habían cumplido medidas de libertad vigilada, ya fuera como medida definitiva, o como resultado de la suspensión del internamiento. Esta muestra estaba integrada en un $80 \%$ por varones y mayoritariamente por jóvenes de nacionalidad española, con un 16,7\% de menores inmigrantes. Una proporción elevada de menores $(40 \%)$ pertenecía a familias con problemáticas, entre moderadas y 
graves, en lo referido a la educación de los hijos así como a circunstancias de drogadicción o comportamiento delictivo de los padres. Un alto porcentaje de menores (64,7\%) presentaba problemas de conducta tales como amenazas o agresiones a compañeros, y también violencia verbal y física con la familia. En un 63,3\% los jóvenes infractores evaluados tenían como amigos a otros chicos y chicas "problemáticos", consumidores de drogas y con frecuentes conductas agresivas y delictivas. Muchos de ellos (hasta un 33,3\%) presentaban trastornos en su desarrollo cognitivo, emocional y comportamental. En relación con el historial delictivo y judicial de los menores, un 56,6\% tenía antecedentes en la Fiscalía o los Juzgados de menores, habiendo cumplido aproximadamente la mitad de ellos medidas previas de libertad vigilada y, en algunos casos, de internamiento.

García, Ortega, \& De la Fuente (2010; Ortega, García, \& de la Fuente, 2009) efectuaron un meta-análisis sobre las tasas de reincidencia (en realidad, su análisis se dirige, en términos positivos, a medir la no reincidencia) de los menores que habían cumplido medidas de justicia juvenil en España. La reincidencia se definió, a efectos de este estudio, como la vuelta del menor al sistema de justicia juvenil, una vez que con anterioridad había sido sentenciado por un delito. En este meta-análisis se integraron 17 estudios previos, publicados entre 1995 y 2008, en los que en total se había evaluado a 16.502 menores. La edad media de los sujetos era 14,68 años y en un 85,75\% eran varones. La tasa promedio de no reincidencia del conjunto de estos estudios españoles, ponderada por sus correspondientes tamaños muestrales, fue de $73,88 \%$, con una desviación típica de 11,27 (es decir, contrariamente, la tasa promedio de reincidencia fue de 26,12\%). Los factores de riesgo que mostraron mayor capacidad explicativa de la reincidencia fueron tener antecedentes penales familiares $\left(\mathrm{R}^{2}=0,81\right)$, haber sufrido maltrato físico $\left(\mathrm{R}^{2}=0,56\right)$, problemas físicos familiares $\left(\mathrm{R}^{2}=0,54\right)$, carecer de trabajo $\left(\mathrm{R}^{2}=0,9192\right)$, uso de violencia en el delito $\left(\mathrm{R}^{2}=0,65\right)$, y tiempo de seguimiento de la reincidencia $\left(\mathrm{R}^{2}=0,86\right)$. Estos datos confirman, en coherencia con la investigación internacional, la multifactorialidad de la conducta delictiva juvenil, para la que no pueden identificarse influencias únicas, sino que diversos factores de riesgo, de distinta naturaleza, parecen contribuir globalmente al riesgo delictivo. 


\subsection{Mayoría de edad}

Es importante señalar, que de acuerdo con los resultados de la Stouthamer-Loeber et al. (2008) y Le Blanc \& Fréchette (1989), el hecho jurídico de la mayoría de edad a los 18 años resulta irrelevante para los procesos de desistimiento del delito. Muchos delincuentes juveniles, incluidos los ya procesados o sentenciados, dejan de delinquir en edades posteriores a los 18 años. Por lo tanto, muchos jóvenes que cometen delitos en las edades de 18 a 20 y son puestos a disposición de la justicia penal adulta (recibiendo por ello sentencias más prolongadas que en el sistema de justicia juvenil), probablemente habrían desistido del delito de forma natural en años sucesivos. De ahí que su procesamiento y condena por el sistema de justicia probablemente los empeora, más que mejorarlos, y contribuye a alargar sus carreras delictivas, más que a reducirlas. Según Piquero et al. (2012), hay consenso en la investigación acerca de que una proporción relevante de delincuentes (de alrededor del 10-30\%) comienza a delinquir durante la primera edad adulta. No obstante, la proporción de delincuentes de inicio adulto varía considerablemente en diferentes estudios (asimismo, dependiendo del criterio de edad adulta que se adopte). Dicha proporción suele ser mayor si se atiende a cifras oficiales de delincuencia que a datos de auto-informe, habida cuenta que muchos delitos juveniles autoinformados no aparecen en los registros oficiales. Por ejemplo, una investigación (Stouthamer-Loeber, 2010) en la que se combinaban datos de autoinforme y oficiales, a partir del Estudio de la juventud de Pittsburgh (PYS), obtuvo que sólo el 3,5\% de los varones había tenido una carrera delictiva entre moderada y grave en la franja de edad de 20 a 25 años, y una proporción suplementaria del 5,4\% había cometido delitos entre moderados y graves en el periodo de los 17 a los 19 años. Sin embargo, estos porcentajes también dependen considerablemente del criterio de delincuencia que se tome. Si se incluyen los delitos menos graves, lógicamente aumenta el porcentaje de quienes pueden ser considerados delincuentes de inicio adulto. Por ejemplo, Blokland \& Palmen (en prensa) evaluaron una muestra de sujetos detenidos por la policía, pero no condenados por delito. A partir de este criterio hallaron que casi la mitad de los detenidos jóvenes-adultos no tenía antecedentes delictivos juveniles, resultado que es concordante con el obtenido por Blumstein et al. (1986). No obstante, Zara \& Farrington (2010) encontraron que un 23\% de los delincuentes de hasta una edad de 50 años había sido condenado por primera vez después de la edad de 21 años. 
Es decir, existe una amplia gama de estimaciones acerca de la prevalencia de inicio tardío en la delincuencia.

En resumen, los estudios sobre persistencia y desistimiento de la delincuencia entre la adolescencia y la primera edad adulta no sustentan que exista una ruptura natural en la prevalencia delictiva a la edad los 18 años (límite legal de la mayoría de edad penal en muchos países). Por otro lado, la persistencia delictiva no es irremediable; las intervenciones fuera del sistema de justicia (que se presentarán más adelante) pueden contribuir al desistimiento del delito de los jóvenes que se hallan en el periodo que media entre la adolescencia y la etapa adulta temprana.

\section{Tipologías especiales de delincuentes}

El Grupo de Estudio en cuyo trabajo se basan los resultados aquí presentados ha analizado también varias categorías de jóvenes delincuentes, incluidos traficantes de drogas, miembros de bandas delictivas, homicidas, y delincuentes sexuales. Las investigaciones muestran diferencias en la carrera criminal de algunas de estas categorías delictivas especiales, aunque no de todas. Por ejemplo, los resultados revisados por Rosenfeld y sus colegas (2012) sobre diversas tipologías delictivas (homicidas, miembros de pandillas, traficantes de drogas y posesión de armas), ponen de relieve que en promedio la edad de inicio de la pertenencia a pandillas, consumo de drogas, posesión de armas y tráfico de drogas es la adolescencia (de 13 a 17 años). Rosenfeld et al. (2012) también sintetizan las secuencias de edades promedio de inicio en las principales categorías delictivas. La menor edad media de inicio correspondería a la pertenencia a pandillas delictivas (promedio 15,9 años), seguida del consumo de marihuana $(16,5)$, tráfico de drogas $(17,0)$, posesión ilegal de armas $(17,3)$ y consumo de drogas duras $(17,5)$.

Aunque los delincuentes por tráfico de drogas suelen ser menos frecuentes en algunos países, el consumo de drogas es común entre casi todos los tipos de delincuentes. Los resultados de la investigación muestran consistentemente que los delincuentes consumen drogas en mayor grado que la población general, y que los consumidores de sustancias tóxicas presentan mayores tasas de delincuencia que los no consumidores (Rosenfeld et al., 2012). De todas las categorías de delitos analizadas, el tráfico de drogas y la posesión de armas mostraron la mayor persistencia desde la adolescencia a la edad adulta. Además, aproximadamente una cuarta parte del inicio en el tráfico de 
drogas, según datos del Estudio de la juventud de Pittsburgh (PYS), tuvo lugar durante la edad adulta (entre 18 y 25 años).

Unirse a una pandilla juvenil suele aumentar la tasa de delitos, pero la participación en pandillas es frecuentemente una experiencia transitoria. La incorporación a pandillas suele producirse en la adolescencia temprana, alcanzando su mayor prevalencia a mediados de esta etapa, y precediendo a la aparición de otras actividades delictivas. Por ejemplo, un estudio encontró que una gran mayoría de jóvenes que se unen a pandillas juveniles lo hacen a edades muy tempranas, por lo general entre los 11 y los 15 años, siendo el intervalo de edad 14-16 años el de mayor participación en ellas (Howell, 2011). En contraste, la mayoría de los homicidios son eventos individuales, no grupales, y son cometidos por jóvenes en el intervalo de 19 a 24 años. Sin embargo, los asesinatos cometidos por pandillas suelen ocurrir durante la adolescencia. Cabe señalar, sin embargo, que la edad de comisión de un homicidio puede ser muy variable.

Rosenfeld et al. (2012), a partir de datos norteamericanos, encontraron que los abusadores sexuales de niños empiezan a cometer estos delitos a edad más avanzada que aquellos que abusan de víctimas de su misma edad y que los agresores sexuales de víctimas adultas. Sin embargo, los abusadores de niños persisten más tiempo en sus delitos en la edad adulta. Bijleveld, van der Geest, \& Hendriks (en prensa) diferencian entre delincuentes sexuales juveniles que efectúan tocamientos, los que abusan de niños y los que abusan de sus compañeros. En esta muestra los abusadores de niños delinquieron más esporádicamente y menos frecuentemente que los abusadores de sus compañeros.

\section{Explicaciones de la transición delictiva}

\subsection{Procesos explicativos}

Se han identificado diez procesos explicativos que pueden ser relevantes a la hora de comprender la transición delictiva desde la delincuencia juvenil a la etapa adulta:

1. Diferencias individuales tempranas en autocontrol.

2. Nivel de maduración cerebral.

3. Cambios cognitivos (por ejemplo, relativos a la toma de decisiones de cambio de conducta). 
4. Factores de riesgo conductuales (como trastornos del comportamiento y conducta antisocial) y factores conductuales de protección (como, por ejemplo, nerviosismo y aislamiento social).

5. Factores sociales de riesgo y de protección (familia, amigos, escuela).

6. Enfermedades mentales y uso / abuso de sustancias.

7. Circunstancias vitales (por ejemplo, casarse o conseguir un empleo).

8. Contexto situacional de hechos delictivos específicos, incluidos los lugares de los delitos y rutinas cotidianas del individuo.

9. Barrio (por ejemplo, vivir en barrios desfavorecidos, o la concentración de personas impulsivas y delincuentes en dichos barrios).

Tabla 2: Orden temporal aproximado de los procesos explicativos en relación con la persistencia delictiva, la desistencia del delito, y la conducta delictiva de inicio tardío.

\begin{tabular}{|c|c|c|c|c|c|c|c|}
\hline & \multicolumn{3}{|c|}{ Infancia } & \multicolumn{3}{|c|}{ Adolescencia } & \multirow{2}{*}{$\begin{array}{l}\text { Edad } \\
\text { adulta } \\
\text { temprana }\end{array}$} \\
\hline & Temprana & Media & Tardía & Temprana & Media & Tardía & \\
\hline $\begin{array}{l}\text { 1. Diferencias } \\
\text { individuales } \\
\text { tempranas }\end{array}$ & & & & & & & $-----\rightarrow$ \\
\hline $\begin{array}{l}\text { 2. Maduración } \\
\text { cerebral }\end{array}$ & ---------- & 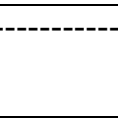 & - & - & -------- & --------- & $-\cdots$ \\
\hline $\begin{array}{l}\text { 3. Factores } \\
\text { conductuales de } \\
\text { riesgo y protección }\end{array}$ & & & & & & & $---\rightarrow$ \\
\hline $\begin{array}{l}\text { 4. Cambios } \\
\text { cognitivos }\end{array}$ & & & & & & & $-------\rightarrow$ \\
\hline $\begin{array}{l}\text { 5. Factores sociales } \\
\text { de riesgo y } \\
\text { protección }\end{array}$ & & - & 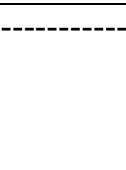 & & 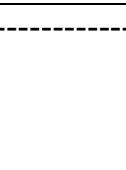 & 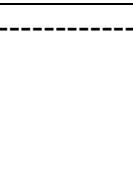 & $-\rightarrow$ \\
\hline $\begin{array}{l}\text { 6. Contexto } \\
\text { situacional }\end{array}$ & & & & 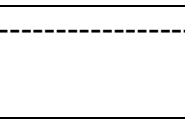 & 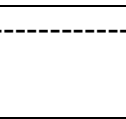 & ------ & 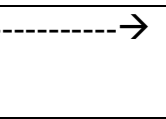 \\
\hline 7. Vecindario & & & ------- & --------------- & ths & --------- & $-\cdots$ \\
\hline $\begin{array}{l}\text { 8. Enfermedad } \\
\text { mental y abuso de } \\
\text { sustancias }\end{array}$ & & & ------ & 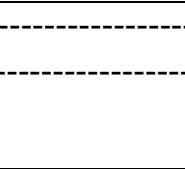 & -------- & -------- & --------- $\rightarrow$ \\
\hline $\begin{array}{l}\text { 9. Respuesta de la } \\
\text { justicia }\end{array}$ & & & & (------- & -'-------- & (------י & $----\rightarrow$ \\
\hline $\begin{array}{l}\text { 10. Circunstancias } \\
\text { vitales }\end{array}$ & & & & & & & 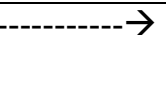 \\
\hline
\end{tabular}


Según se ha visto ya, muchos jóvenes cometen algunos actos ilícitos en su adolescencia, pese a lo cual son afortunadamente muy pocos los que persisten en la actividad delictiva e incrementan la gravedad de sus acciones (Moffit, 1993). A partir de los estudios longitudinales en delincuencia, que son aquéllos que efectúan un seguimiento de una determinada cohorte de sujetos desde su infancia hasta la vida adulta, se ha estimado que aproximadamente un $5 \%$ de todos los adolescentes que han cometido alguna infracción persisten en la delincuencia, devienen delincuentes adultos y son los responsables de más de la mitad de todos los delitos que se cometen en una sociedad (Farrington, 2008; Howell, 2011). Atendida esta realidad bastante universal, la pregunta clave es qué es lo que hace que esa minoría de sujetos se convierta en delincuentes graves y crónicos, mientras que la mayoría de los jóvenes que han cometido algunas infracciones adolescentes desiste pronto de tales actos ilícitos.

Una respuesta plausible a lo anterior, a la luz del conocimiento actual, es que la transformación de algunos sujetos en delincuentes crónicos va a depender esencialmente del grado de "motivación antisocial" o delictiva que tengan, a partir del número de factores de riesgo que confluyan en ellos. Una operativización del constructo “motivación antisocial” se ha propuesto por Redondo (2008), en su Modelo del Triple Riesgo Delictivo (TRD). En él se establece que los factores de riesgo que contribuyen a promover las carreras delictivas pueden ser categorizados en tres fuentes de riesgos: a) riesgos en "disposiciones y características personales", b) carencias en el "apoyo prosocial" recibido por los individuos, y c) "oportunidades delictivas" a las que los sujetos se ven expuestos. En concreto, según el Modelo del Triple Riesgo Delictivo, la motivación antisocial de un sujeto sería el resultado de la confluencia en él de riesgos personales y carencias en el apoyo prosocial recibido. Para el análisis del riesgo fehaciente de conducta infractora, se requeriría además tomar en consideración las “oportunidades" delictivas concretas a las que el individuo se ve expuesto.

Atendida la diversidad de fuentes de riesgo aludida, es fácil hacerse una idea de la multicausalidad de la conducta delictiva, y, en consecuencia, de la complejidad que asimismo tiene su prevención. Los riesgos personales (que incluyen características individuales como impulsividad, pensamientos justificadores del delito, o reacciones emocionales de ira) van a necesitar intervenciones educativas y de tratamiento directas con los individuos. Los factores de riesgo relativos a las carencias en el apoyo prosocial 
(con aspectos como inapropiada crianza paterna, desvinculación escolar, amigos delincuentes, barrios deteriorados, etcétera) van a requerir programas y mejoras sociales de amplio espectro, cuyos efectos preventivos sobre la reducción de la delincuencia juvenil sólo podrán concretarse a medio y largo plazo. Por último, las oportunidades delictivas exigen también sus propias medidas de prevención ambiental, mejorando los controles sociales informales, tanto personales como relativos a medidas físicas de evitación del delito.

\subsection{Género}

De forma universal una minoría de quienes delinquen corresponde a chicas y mujeres con problemas y necesidades que a menudo son diferentes de las de los varones delincuentes, ya sean jóvenes o adultos. Además, es discutible hasta qué punto las carreras delictivas y las causas de la delincuencia son las mismas para ambos sexos, y si los programas de intervención con hombres y mujeres son igualmente eficaces. Las intervenciones específicas con división de géneros son escasas y existen muy pocos estudios sobre la efectividad de las intervenciones con mujeres (Hipwell \& Loeber, 2006; Zahn, Day, Mihalic, \& Tichavsky, 2009). Con todo, un meta-análisis reciente ha concluido que los programas de intervención genéricos (por ejemplo, terapia cognitivoconductual, terapia individual, y similares) resultan efectivos en igual medida con los varones y las chicas (Lipsey, 2009). Hipwell \& Loeber (2006) hallaron cierta evidencia de que las intervenciones diseñadas específicamente para la delincuencia femenina y los programas multimodales pueden ser eficaces con mujeres jóvenes.

Bartolomé, Montañés, Rechea, \& Montañés (2009) evaluaron a 642 jóvenes escolarizados de ambos sexos, con los objetivos de analizar las semejanzas y diferencias en su comportamiento infractor, así como si varones y mujeres están expuestos a diferentes factores de riesgo y protección, o si estos influyen de manera distinta en su comportamiento. La primera constatación fue que los varones y las chicas mostraron comportamientos ilícitos diferentes. En concreto, los chicos se habían involucrado más frecuentemente en peleas, portar posibles armas y realizar más conductas vandálicas. En segundo término, las chicas evidenciaron contar con más factores de protección: mayor supervisión paterna, más interés en seguir estudiando, y un estilo de resolución de problemas más comunicativo y pacífico. Mediante un análisis de regresión logística se comprobó que la variable sexo (ser chica, en este caso) tenía una importante capacidad 
protectora, independientemente de la exposición o no de los sujetos a otros factores de riesgo. Dado que los chicos contaban en general con menos factores protectores, cuando éstos se hallaban presentes producían un firme efecto protector. Aspectos como la participación en la vida escolar, la supervisión familiar y tener una buena relación con el padre operaban como protectores sobre los chicos, y contar con amigos prosociales y tener objetivos de futuro influían más, como factores protectores, sobre las chicas.

Diversas cuestiones importantes relacionadas con el género se abordarán en un próximo artículo de esta serie.

\subsection{Origen étnico}

Existen muchos acuerdos y algunos malentendidos acerca de la importancia de la etnia en la transición desde la adolescencia a la adultez temprana. Por ejemplo, en Norteamérica los estudios muestran que los varones afroamericanos alcanzan su máximo delictivo antes y con mayor intensidad en la curva de la edad del delito que las mujeres afro-americanas y que los varones caucásicos. Asimismo, los jóvenes varones afroamericanos cometen homicidios y son víctimas de homicidio en mayor grado que los caucásicos (Anderson \& Smith, 2002; Fox \& Zawitz, 2007). No obstante, las diferencias entre etnias en delincuencia pueden ser explicadas por la diversa incidencia que tienen en las distintas etnias los factores de riesgo. Loeber \& Farrington (2011) mostraron que, en comparación con los niños caucásicos, los afro-americanos presentaban mayores privaciones en factores socioeconómicos / demográficos, tales como hogar roto, familia dependiente de los servicios sociales, barrio problemático, y madre muy joven. Otros análisis de los datos del Estudio de la juventud de Pittsburgh (PYS) han puesto de relieve que, si se toman en cuenta otros factores sociales y estructurales, la raza/etnia no predice la violencia (Huizinga et al., 2006) ni el homicidio (Loeber \& Farrington, 2011). También la cuestión de la relación entre etnia y delito se explorará con más detalle en otro artículo posterior de esta serie.

\subsection{Desistencia e inicio tardío en el delito}

El Grupo de Estudio se planteó tres cuestiones clave: a) ¿Cuáles son los procesos que explican la persistencia de la conducta delictiva desde la adolescencia hasta la edad adulta? b) ¿Cuáles son los procesos que explican el desistimiento durante ese mismo 
periodo? Y c) ¿Cuáles son los mecanismos que explican el inicio tardío en el delito durante la edad adulta?

Existen múltiples procesos que influyen sobre la continuidad de la conducta antisocial entre la adolescencia y la edad adulta temprana. La persistencia en la delincuencia podría explicarse por varios de ellos, incluyendo, como se vio en la Tabla 2, diferencias individuales tempranas, factores de riesgo conductuales, exposición de los individuos a factores sociales de riesgo, retraso madurativo del cerebro, y respuesta de la justicia.

Sin embargo, sólo algunos procesos están relacionados con el desistimiento del delito, como por ejemplo la existencia de características individuales favorables y la exposición a pocos factores de riesgo conductuales. Además, la maduración cerebral temprana y los cambios cognitivos fomentarían el desistimiento. También existe firme evidencia empírica de que, para los varones, casarse o iniciar una relación de pareja y tener un trabajo estable favorecen la desistencia delictiva, mientras que la presencia frecuente en actividades no estructuradas con amigos se asocia a la persistencia de la conducta antisocial. Por ejemplo, Horney, Tolan, \& Weisburd (2012) mostraron que para los varones, el matrimonio generalmente se vincula a una reducción de las conductas delictivas y de consumo de sustancias, asociación que es menos clara para el caso de las mujeres. En cambio, las conclusiones sobre el posible impacto del empleo en la delincuencia muestran menos consistencia. No todos los estudios confirman que el empleo fomente el desistimiento del delito o el abandono del consumo de sustancias. Mayor información existe de lo contrario, que los periodos de desempleo se asocian a mayor delincuencia tanto en los jóvenes como en los adultos (por ejemplo, Farrington et al., 1986). Por otro lado, mientras que hay firme evidencia de que la mayor presencia de factores de riesgo dificulta el desistimiento delictivo durante el periodo adolescenciaadultez temprana, es menos claro que los factores de protección fomenten el desistimiento.

Desafortunadamente, la escasa investigación disponible sobre inicio tardío en el delito poco permite concluir acerca de qué factores explican que algunos individuos que no habían cometido delitos en la adolescencia se conviertan en delincuentes adultos. Sin embargo, existe cierta información contrastada de que algunos factores inhiben la delincuencia durante la adolescencia, pero no en la edad adulta. Zara \& Farrington (2009) encontraron que características tales como nerviosismo, ansiedad, aislamiento social e inhibición social se asociarían a un inicio adulto en el delito. 
Las explicaciones que se revisan aquí tienden a ser de utilidad para comprender periodos diferentes entre la infancia y la edad adulta, pudiendo dar lugar a resultados distintos aunque relacionados entre sí (Tabla 2). Por ejemplo, las diferencias individuales tempranas se muestran desde el nacimiento evolucionando posteriormente, la exposición a nuevos factores de riesgo aumenta desde la infancia hasta la adolescencia, mientras que los cambios en circunstancias vitales favorables - como el matrimonio y el empleo - se hacen paulatinamente más probables desde la adolescencia tardía hasta bien entrada la edad adulta temprana.

Ninguno de los estudios longitudinales publicados hasta la fecha ha especificado la contribución relativa a la conducta delictiva de cada uno de estos procesos que suceden desde la infancia hasta la edad adulta temprana. Para el caso de aquellos mecanismos explicativos que son moldeables (por ejemplo, la calidad de la supervisión paterna, el autocontrol, o el empleo juvenil), no se conoce cuáles de ellos, al hacerse más favorables, pueden ser más eficaces en la reducción de la persistencia delictiva de los jóvenes. En un trabajo posterior de esta serie se especificará con detalle la eficacia de las intervenciones preventivas y de tratamiento con delincuentes jóvenes.

Es importante remarcar que, tal y como ya se comentó, ninguno de los procesos mencionados, que operan durante la transición entre la adolescencia y la adultez temprana, se circunscribe a la línea divisoria de la edad de 18 años, que es la distinción más aceptada entre la adolescencia y la edad adulta, y entre la intervención de los sistemas de justicia juvenil y el sistema penal adulto. Por el contrario, esta división cronológica resulta poco relevante para la mayoría de las evoluciones que tienen lugar alrededor de ella, tales como la maduración del cerebro y el tránsito desde el control externo del comportamiento hacia el control interno.

Existen diferencias temporales importantes entre los jóvenes en su proceso de maduración. Por ello, el Grupo de Estudio se planteó la siguiente cuestión: ¿Qué categorías de jóvenes maduran más lentamente en su capacidad cognitiva de control de la conducta y tardan más tiempo en desistir del delito? Bijleveld et al. (en prensa) han examinado nuevos resultados de investigación acerca de grupos vulnerables, incluidos jóvenes que estuvieron internados en instituciones de menores, y jóvenes con bajo nivel intelectual. Comprobaron que ambos grupos presentaban carreras delictivas más prolongadas y fueron condenados más frecuentemente que los grupos de comparación. Los jóvenes con baja inteligencia requieren atención especial, no sólo porque sean 
menos capaces de entender los procedimientos judiciales, sino también porque tienden a presentar mayor impulsividad cognitiva y acaban siendo procesados por un mayor número de delitos (Koolhof, Loeber, Wei, Pardini, \& Collot d'Escury, 2007).

\section{Evaluaciones riesgo-necesidades}

Las evaluaciones de riesgo a menudo tienen como finalidad ayudar a los jueces de menores en la toma de decisiones sobre los jóvenes delincuentes. Ello es coherente con un enfoque individualizado y rehabilitador de los tribunales de menores. También se utiliza la evaluación de riesgo de menores y adultos en contextos institucionales (incluidos los centros de salud mental) para informar las decisiones relativas a su posible liberación anticipada. En consecuencia, el objetivo principal de muchos instrumentos de evaluación de riesgo es predecir la probabilidad de reincidencia delictiva. Sin embargo, no existen instrumentos específicamente diseñados para predecir la persistencia delictiva de los menores durante la edad adulta temprana. Por otro lado, en la mayoría de los estudios de reincidencia, el periodo de seguimiento de la conducta delictiva ha sido muy corto (a menudo un año). Además, la evaluación del riesgo escasamente se emplea para informar a los tribunales en los procedimientos penales adultos, debido a su mayor orientación punitiva. A pesar de todo, las evaluaciones de riesgo podrían tener gran utilidad para el caso de los delincuentes jóvenes adultos, ya que algunos de ellos presentan baja probabilidad de reincidencia por el simple efecto de la disminución delictiva que se asocia a la curva de edad del delito.

Existen instrumentos bien calibrados para evaluar la capacidad de los jóvenes para afrontar un proceso judicial, y para asesorar en el procedimiento de la sentencia penal o la posterior liberación condicional. Sin embargo, se sabe relativamente poco acerca de qué instrumentos pueden ser más adecuados para evaluar a los jóvenes adultos. Las evaluaciones de riesgo se efectúan a menudo en conjunción con las evaluaciones de necesidades para valorar la capacidad de los delincuentes para enfrentar un juicio, para medir su inteligencia o para evaluar problemas de salud mental. Lo anterior se sustenta en la idea básica de que los jóvenes vulnerables deberían ser tratados individualmente en los tribunales y tendrían que recibir servicios especializados adecuados, como, por ejemplo, el tratamiento de sus posibles trastornos mentales. También se deberían 
desarrollar instrumentos de evaluación fiables y válidos para valorar la maduración cognitiva y cerebral de los jóvenes.

\section{Prevención y tratamientos con delincuentes}

\subsection{Intervenciones tempranas}

Una pregunta crucial es si los programas que se realizan fuera del sistema de justicia, en la comunidad, reducen el riesgo de delincuencia, y en particular la persistencia delictiva, en el periodo que media entre la adolescencia y la adultez temprana. ¿En qué grado son efectivos los programas familiares que se aplican en la niñez temprana para reducir la delincuencia en la etapa joven-adulto? Existe evidencia contrastada de que las intervenciones tempranas en la infancia (como por ejemplo las consistentes en visitas domiciliarias de una enfermera especializada al efecto de la mejora del cuidado del neonato, los programas de enriquecimiento intelectual en edad preescolar, o el entrenamiento paterno en crianza infantil) resultan eficaces en la prevención de la delincuencia. Por ejemplo, Welsh et al. (2012) examinaron la utilidad de la educación infantil recibida a partir de visitas domiciliarias efectuadas por una enfermera desde la etapa del embarazo de la madre a los primeros años de vida del niño, en el marco de un experimento aleatorio desarrollado por Olds y sus colegas para evaluar el programa Interacción Familia-Enfermera, en Elmira, New York (Elmira Nurse Family Partnership program). A los 15 años, los hijos de madres de alto riesgo que habían recibido visitas domiciliarias sumaban un número de detenciones significativamente menor que los sujetos del grupo control (cuyas madres no recibieron dichas visitas). Un seguimiento posterior de estos jóvenes, a la edad de 19 años, halló que las hijas (pero no los hijos varones) cuyas madres habían recibido visitas domiciliarias contaban con menos detenciones y condenas. Pese a todo, en este estudio no se evaluó específicamente si los niños que recibieron la intervención temprana cometieron menos delitos durante su etapa, algo posterior, como jóvenes-adultos.

¿Resultan efectivos los programas infantiles individualizados para reducir la delincuencia en el periodo joven-adulto? Las mejores evaluaciones de programas de intervención infantil temprana en comparación con controles sin tratamiento han mostrado reducciones de la conducta delictiva que se mantuvieron hasta la edad adulta. Welsh y sus colegas (2012) destacaron los resultados obtenidos por un programa de intervención temprana denominado Proyecto de Desarrollo Social de Seattle (Seattle 
Social Development Project, SSDP), que combinaba entrenamiento de padres, formación del profesorado y entrenamiento en habilidades a los niños a partir de la edad de seis años. A la edad de 27 años, el grupo de intervención puntuó significativamente mejor en nivel educativo y económico, salud mental y salud sexual, pero no en abuso de sustancias o delincuencia (Hawkins et al., 2008).

¿En qué grado son efectivas las intervenciones comunitarias y escolares para reducir la delincuencia de los jóvenes-adultos? Algunas intervenciones basadas en el control escolar, aunque no todas, ha producido reducciones de la delincuencia durante la transición entre la adolescencia y la etapa adulta temprana. No obstante, se requieren más investigaciones para conocer cuáles son los mejores programas de este ámbito (por ejemplo, Comunidades que cuidan -Communities That Care-, programas de orientación y otros). Programas de empleo, como el denominado Corporaciones de empleo (Job Corps), son en general eficaces en la reducción de los delitos cometidos por jóvenes adultos.

Un meta-análisis sobre treinta y cuatro programas dirigidos a favorecer el autocontrol en niños de hasta 10 años de edad evidenció una mejora significativa del autocontrol y una reducción de la conducta delictiva (Piquero, Jennings, \& Farrington, 2010). El autocontrol es moldeable, al menos parcialmente, y su mejora produce beneficios a largo plazo. Sin embargo, resulta menos claro hasta qué punto la mejora del autocontrol se asocia a una maduración cerebral acelerada, a una más rápida superación de la impulsividad y las conductas de búsqueda de sensaciones durante la adolescencia, a un descenso individual de la curva de edad del delito, y a un acortamiento de la curva edaddedito durante la edad adulta temprana.

¿En qué medida son efectivas son las intervenciones con delincuentes juveniles (en las edades 14-17) para prevenir la continuación hacia la delincuencia juvenil-adulta? Tres tipos de intervenciones, la Terapia multisistémica (Multisystemic Therapy, MST), el Tratamiento enfocado a supervisar el proceso de crianza (Treatment Foster Care, TFC), y la Terapia familiar funcional (Functional Family Therapy, FFT), han mostrado reducir la reincidencia en la edad adulta temprana. Por ejemplo, Welsh y sus colegas (2012) obtuvieron evidencia de que la TMS es eficaz en la prevención de la reincidencia. Por otro lado, a partir de un experimento aleatorio en el que se efectuó un seguimiento a largo plazo de los sujetos entre las edades de 14 y 28 años, Schaeffer \& Borduin (2005) encontraron que los participantes en Terapia multisistémica claramente 
presentaron menores tasas de reincidencia (50\% versus $81 \%$ ), incluida una menor proporción de nuevas detenciones por delitos violentos (14 \% versus 30\%). Los participantes en Terapia multisistémica MST también acabaron estando menos días recluidos (un 57\% menos) en centros de detención de adultos.

La terapia multisistémica (MST) fue concebida por Henggeler y sus colaboradores (Edwards, Schoenwald, Henggeler, \& Strother, 2001; Henggeler \& Borduin, 1990), a partir de interpretar el desarrollo infantil bajo la influencia de las diferentes capas ambientales -familia, escuela, instituciones del barrio, grupos religiosos, sociedad- que se van solapando. Se considera que los individuos "anidan" entre todos estos sistemas interrelacionados (individual, familiar, extrafamiliar y de los amigos), los cuales influyen sobre su desarrollo y su comportamiento de maneras recíprocas. En estos diversos sistemas existirían tanto factores de riesgo como factores de resistencia o fortalecimiento (Edwards et al., 2001). Desde esta perspectiva, se interpreta que los problemas de conducta se mantendrían debido a la aparición de transacciones problemáticas, ya sea específicamente en uno de estos sistemas o bien en alguna de sus posibles combinaciones. Las intervenciones propuestas por la terapia multisistémica se desarrollan en la propia familia, o en las interacciones de ésta con los otros sistemas relacionados (escuela, grupo de amigos, barrio y comunidad más amplia) (Littell, 2005). La terapia multisistémica utiliza todas aquellas técnicas terapéuticas que han mostrado mayor eficacia empírica con delincuentes juveniles, es decir, técnicas esencialmente cognitivo-conductuales: reforzamiento, modelado, reestructuración cognitiva, control emocional, etcétera. Al igual que otras terapias familiares, la terapia multisistémica se aplica en lugares de conveniencia de las propias familias (la propia casa, la escuela, una iglesia, un local del barrio) con la finalidad de facilitar al máximo la participación de los miembros familiares (Edwards et al., 2001). La terapia implica contactos intensivos y frecuentes, a veces diarios, y cada terapeuta se encarga de entre 4 y 6 familias. Durante los últimos años ha habido numerosas evaluaciones de la terapia multisistémica, que han obtenido los mejores resultados existentes hasta el momento en el tratamiento de los delincuentes juveniles y otros problemas de conducta tales como adicción a drogas (Cullen \& Gendreau, 2006; Schoenwald, Heiblum, Saldana, \& Henggeler, 2008).

¿Llevar a cabo intervenciones tempranas reduce la curva de la edad del delito? Una de las limitaciones de los estudios evaluativos al respecto es la ausencia de seguimientos anuales de los individuos tratados y no tratados durante la adolescencia y la adultez 
temprana. Por esa razón, las evaluaciones publicadas hasta ahora no han podido mostrar el grado en que las intervenciones reducen la curva de edad del delito. Para resolver este problema, Loeber \& Stallings (2011) han utilizado datos longitudinales del Estudio de la juventud de Pittsburgh (PYS) para simular el impacto que podría tener una intervención rehabilitadora adecuada sobre los delitos cometidos por jóvenes en riesgo. A partir de esta simulación rehabilitadora pudo establecerse que la intervención con jóvenes en riesgo del Estudio Pittsburgh reduciría sustancialmente la curva de edad del delito durante la adolescencia y la etapa adulta temprana, produciendo una menor prevalencia de delincuentes graves autoinformados, una disminución del número de homicidas y de eventuales víctimas de homicidio, y una reducción de las detenciones y las condenas en el marco del sistema de justicia.

En conclusión, existen múltiples intervenciones comunitarias, fuera del sistema de justicia, susceptibles de reducir la reincidencia y evitar la persistencia delictiva entre la adolescencia y la adultez temprana. Los resultados anteriores indican que tales intervenciones pueden reducir la curva de edad del delito.

\subsection{Costes y beneficios económicos de las intervenciones}

¿Qué se sabe acerca de los beneficios y costes económicos de las diferentes intervenciones que podrían reducir la delincuencia en los años de la edad adulta temprana? Una revisión de estudios de costo-beneficio realizada por Welsh y sus colegas (2012) concluyó que los beneficios económicos derivados de algunos programas pueden ser mayores que sus costos. Tal fue el caso, por ejemplo, del tratamiento multidimensional de supervisión de la crianza (MTFC) (con un rendimiento económico de 8 dólares ahorrados por cada dólar invertido), la terapia familiar funcional (FFT) (con 10 dólares ahorrados por cada dólar gastado), la terapia multisistémica (MST) (que economizó 3 dólares por cada uno empleado), la formación profesional en prisión (con un beneficio de 12 dólares por cada uno invertido), la terapia cognitivo-conductual en la prisión (con un extraordinario rendimiento de 22 dólares ahorrados por cada uno gastado), el tratamiento penitenciario con toxicómanos (con un ahorro de 6 dólares por cada dólar invertido), y la formación para el empleo en la comunidad (con 12 dólares de beneficio por cada uno gastado). Lo anterior pone de relieve que muchos programas no sólo reducen la delincuencia en la edad adulta 
temprana, sino que a largo plazo también pueden ahorrar a los contribuyentes mucho dinero.

\section{Prioridades para la investigación}

Una de las constataciones de este estudio es que hay importantes lagunas en el conocimiento de las carreras delictivas entre los 15 y los 29 años. Poco se sabe (sobre todo a partir de auto-informe) sobre la prevalencia, frecuencia, tipo de delitos, codelincuencia, motivos para delinquir, especialización, intensificación y persistencia, en contraposición al desistimiento, la intermitencia y el inicio tardío en el delito. Sorprendentemente incluso se carece de información acerca de cuestiones tan básicas como qué cantidad de delincuentes juveniles (de entre 15-17 años) persisten en la delincuencia adulta (de 18 en adelante), y qué factores de riesgo en la edad juvenil pueden predecir la persistencia delictiva en la edad adulta. Sería imprescindible conocer mejor los procesos que pueden favorecer la conducta delictiva entre las edades de 15 a 29, especialmente en lo referido a los factores de riesgo individuales (incluidos los que tienden a desarrollarse con la edad, tales como madurez psicosocial, control de los impulsos, procesos cognitivos de toma de decisiones, funciones ejecutivas, tendencia al riesgo, regulación emocional, y posibles problemas de salud mental). Asimismo debería saberse más sobre aquellas circunstancias vitales relativas a educación, empleo, relaciones de convivencia y pareja, consumo de drogas y relaciones personales, que pueden contribuir al desarrollo de la delincuencia. Por último, también habría que comprender mejor cómo las actividades cotidianas de los individuos y sus contextos vecinales y situacionales influyen sobre la actividad criminal.

Se recomiendan aquí dos formas de avanzar en el conocimiento sobre el desarrollo de las carreras delictivas y sus factores de influencia. La primera y más inmediata sería efectuar análisis secundarios de los datos longitudinales ya existentes e investigar en qué medida los cambios en los factores que influyen sobre los individuos concretos son seguidos de cambios en su actividad delictiva. Son pocos los estudios que han efectuado análisis intra-individuales, algo que requiere evaluaciones repetidas de los sujetos a lo largo del tiempo.

Sin embargo, los análisis secundarios de información preexistente no permiten abordar todas las cuestiones clave planteadas en los artículos que se publicarán a lo largo de esta serie, que abarcan un amplio espectro que va desde los procesos de maduración 
psicosocial de los propios individuos hasta los análisis del vecindario y las influencias situacionales sobre el delito. Por ello, nuestra segunda recomendación es animar a distintos equipos de investigación a iniciar y desarrollar dos estudios longitudinales paralelos, uno sobre una muestra comunitaria, o de población general, y el otro de una muestra de delincuentes (este método dual ya fue utilizado con anterioridad por Marc Le Blanc en Quebec). Ambos tipos de estudios tienen ventajas y desventajas complementarias. El estudio sobre una muestra comunitaria permitiría generalizar sus resultados a la población general, pero no posibilitaría conocer las casuísticas de delincuentes más peligrosos. Inversamente, el estudio sobre una muestra delictiva proporcionaría gran información sobre los delincuentes de inicio temprano, pero sus resultados serían poco generalizables al conjunto de la población y no permitirían evaluar las características de los delincuentes de inicio tardío. Si los dos estudios propuestos se realizaran en el mismo lugar y periodo temporal con jóvenes de edad similar, se podrían extraer conclusiones válidas sobre los delincuentes juveniles y sobre la población en su conjunto. Estas investigaciones podrían inspirarse respectivamente en el Estudio de la juventud de Pittsburgh (PYS), desarrollado en la comunidad, y en el Estudio sobre trayectorias hacia el desistimiento delictivo (Pathways to Desistance Study), que es probablemente la investigación longitudinal más importante realizada con delincuentes juveniles.

Nuestras sugerencias complementarias son que ambos estudios se llevaran a cabo en una misma ciudad, de tamaño grande (y en la que la mayoría de edad legal sean los 18 años), con bajas tasas de inmigración y emigración, con los objetivos de facilitar la retención de la muestra (es decir, evitar en lo posible la mortalidad experimental) y permitir el análisis de los factores vecinales, situacionales y contextuales. Idealmente, los estudios propuestos deberían desarrollarse en paralelo en más de una ciudad, como en el caso del Programa de investigación sobre causas y correlatos de la delincuencia (OJJDP Program of Research on the Causes and Correlates of Delinquency). Este proyecto podría realizarse de dos formas distintas, una más ambiciosa o ideal y otra más realista. Ideal sería efectuar el seguimiento de un gran número de varones y mujeres de diferentes grupos raciales / étnicos, pero tal vez es más realista y factible limitar cada estudio (al menos inicialmente) al seguimiento de unos 500 varones y unas 1000 mujeres. En el estudio comunitario podría efectuarse un sobremuestreo de jóvenes de alto riesgo para aumentar así la información obtenida sobre los delincuentes, al mismo 
tiempo que todavía permitiría la generalización a la población general. Por su lado, el estudio sobre delincuentes podría basarse en datos sobre jóvenes procesados por los tribunales de menores. En el formato ideal los jóvenes deberían ser evaluados anualmente mediante entrevistas directas realizadas entre las edades de 15 a 29 años, pero de forma más realista las entrevistas (en total unas 6) podrían efectuarse cada dos años entre las edades de 15 y 24 años. Deberían recogerse datos mediante repetidos auto-informes y documentos oficiales sobre las posibles actividades delictivas de los sujetos, para lo que sería crucial contar con la cooperación de los organismos oficiales correspondientes.

Los principales objetivos que podrían tener estos estudios se resumen en el Recuadro 1.

Algunos de estos objetivos podrían ser abordados con mayor eficacia en la muestra comunitaria, y otros en la muestra de delincuentes.

Recuadro 1: Objetivos de los estudios longitudinales propuestos, que se orientan al análisis de la transición entre la delincuencia juvenil y la delincuencia adulta:

1. Estudiar el desarrollo de las carreras delictivas entre los 15 y los 25 años, evaluando para ello prevalencia, frecuencia, tipo de delitos, co-delincuencia, motivos para delinquir, especialización delictiva, intensificación delictiva, persistencia en contraste con desistimiento, intermitencia e inicio adulto en el delito.

2. Comparar datos de auto-informe y cifras oficiales sobre carreras delictivas.

3. Obtener información sobre las principales interacciones predictivas entre factores de la carrera delictiva como, por ejemplo, en qué grado la probabilidad de persistencia o desistimiento delictivos a cada edad, y la duración residual de la carrera criminal, varían en función de características tales como la edad de inicio o el tiempo transcurrido desde el último delito. Particularmente interesa conocer en qué medida la carrera criminal adulta puede predecirse ya a la edad de 17 años.

4. Estudiar la relación entre conducta delictiva y factores individuales tales como funciones ejecutivas, desarrollo neurobiológico y cerebral, factores cognitivos, toma de decisiones, impulsividad, autocontrol, madurez psicosocial, regulación emocional y competencia para la toma de decisiones.

5. Evaluar la solidez de las relaciones entre factores de riesgo (individuales, familiares, amigos, escuela, vecindario y comunidad), eventos y transiciones vitales (por ejemplo, empleo, matrimonio, comenzar a vender drogas o participar en pandillas) y las características de la carrera delictiva subsiguiente.

6. Analizar el desarrollo de los sujetos en diferentes comunidades y barrios.

7. Evaluar los factores situacionales, rutinas de vida, y oportunidades que influyen en que una persona con cierto potencial antisocial cometa un delito en un momento y lugar concretos.

8. Estudiar los factores que influyen en las transiciones exitosas hacia los roles adultos, tales como acceder a un empleo, disponer de un alojamiento adecuado, casarse o tener una pareja, o la experiencia de la paternidad.

9. Evaluar los efectos de diferentes tipos de procesamiento judicial (por ejemplo, de juzgados de menores frente a tribunales de adultos, distintas medidas aplicadas, etcétera) en las diferentes edades, empleando para ello comparaciones cuasi-experimentales y el emparejamiento de sujetos semejantes para amortiguar los sesgos de selección.

10. Evaluar la precisión que tienen los instrumentos de evaluación de riesgo/necesidades para la predicción de la persistencia delictiva o del desistimiento. 
11. Valorar la eficacia de diferentes tipos de intervenciones, dentro y fuera del sistema de justicia de menores o adultos, para distintas edades.

12. Evaluar los beneficios y costes económicos de los diversos tipos de intervenciones y medidas judiciales.

13. Estudiar cómo varían las carreras delictivas y otras magnitudes de las conductas delictivas en función de la raza / etnia y el género.

\section{Recomendaciones de política criminal}

A continuación se presentan diversas recomendaciones que podrían ser pertinentes para reducir la población carcelaria, especialmente a partir de disminuir el flujo de menores desde el sistema de justicia juvenil hacia el sistema penitenciario adulto.

Existen razones importantes para que los delincuentes jóvenes sean tratados de una forma distinta a los delincuentes adultos, tanto en tribunales propios como, posteriormente, en los centros penitenciarios. En el Recuadro 2 se resumen las características más importantes que diferencian a los menores de los adultos, que en opinión del Grupo de Estudios NIJ deberían ser tomadas en cuenta al adoptar decisiones judiciales relativas a menores y jóvenes que han infringido la ley.

\section{Recuadro 2: Características de los menores que pueden ser relevantes para las decisiones judiciales:}

1. Que el menor tenga una madurez de juicio reducida.

2. Que presente limitada capacidad de toma de decisiones frente a las oportunidades delictivas que se le presentan.

3. Pobres funcionamiento ejecutivo, razonamiento, pensamiento abstracto, y planificación.

4. Mayor susceptibilidad a la influencia de gratificaciones inmediatas que al influjo de posibles consecuencias indeseables a largo plazo.

5. Pobre control de impulsos, menor propensión a asumir riesgos y a cometer delitos por diversión más que en función de decisiones racionales.

6. Menor estabilidad de los hábitos delictivos, mayor modeabilidad, mayores posibilidades de recuperación.

7. Menor culpabilidad, responsabilidad disminuida, menos merecedor de castigo.

8. Pobres emocionabilidad y autorregulación.

9. Menor evitación del propio daño.

10. Menor capacidad para comunicarse con abogados, tomar decisiones legales, comprender y participar en los procedimientos legales y en el juicio oral.

11. Mayor susceptibilidad a la influencia de los compañeros.

Los delincuentes jóvenes-adultos, con edades entre 18-24 años, se asemejan más a los menores que a los adultos con respecto a su actividad delictiva, madurez personal y diversas circunstancias de la vida. Por ello se hacen las siguientes recomendaciones de política criminal, muchas de ellas dirigidas a mejorar la situación en esta materia en 
Estados Unidos, aunque algunas también resultan pertinentes para los países europeos y en particular para España:

1. Se deberían efectuar cambios legislativos para hacer frente a un gran número de menores delincuentes en riesgo de devenir delincuentes adultos. Una posibilidad sería aumentar la edad mínima para la remisión de los jóvenes a un tribunal de adultos a 2124 años, con el objetivo de que menos jóvenes delincuentes arriben al sistema de justicia penal adulto. Lo anterior podría producir importantes beneficios: menos delincuentes juveniles serían encarcelados y expuestos a las influencias criminógenas de la prisión, un mayor número podría recibir penas alternativas, no sanciones de internamiento, y más jóvenes podrían participar en programas paralelos, orientados al desarrollo de habilidades positivas. De este modo cabría esperar que el número de presos adultos se redujera y que de ello resultara un sustancial ahorro económico para los contribuyentes. En EE.UU., y en general en los países desarrollados, deberían efectuarse análisis costo-beneficio para cuantificar las ventajas que se derivarían de elevar la edad legal de la jurisdicción de menores a entre 21 y 24 años. Un análisis costo-beneficio de estas características se ha efectuado ya en el Reino Unido.

Por lo que concierne a Europa existen grandes diferencias en los países europeos en relación con las medidas legales previstas para los jóvenes delincuentes (Killias, Redondo, \& Sarnecki, 2012). En España y en la mayor parte de Europa la edad de responsabilidad penal juvenil se sitúa en los 14 años, momento a partir del cual el joven infractor entra en el sistema de justicia juvenil. Aun así, desde una perspectiva europea comparada la edad de responsabilidad penal juvenil es muy diversa: hay países en que puede iniciarse a los 8 o 10 años (como en el caso de Chipre, Grecia, Suiza o Reino Unido), mientras que en otros se eleva a 16 años e, incluso, a 18. También la edad de responsabilidad penal completa, en que debe aplicarse la ley penal adulta (que en general se sitúa en torno a los 18/21 años) es muy heterogénea entre países. Por ejemplo, Dinamarca, Finlandia, Islandia o Noruega establecen que los jóvenes mayores de 14 o 15 años pueden ser juzgados como adultos. En cambio, Alemania y Austria permiten que jóvenes de 18 y 20 años sean juzgados bajo el sistema de justicia juvenil. Según el análisis de 31 países europeos realizado por Killias et al. (2012) en Europa coexisten dos sistemas de justicia juvenil bien distintos, entre los que España ocuparía una posición intermedia. Por un lado, algunos países tienen un sistema más duro y punitivo, permitiendo la ejecución de medidas muy largas con jóvenes infractores 
mayores de 16 años o, incluso, la aplicación de la ley penal adulta. Contrariamente, otro conjunto de países dispone de un sistema de justicia juvenil con medidas más cortas y orientadas a la resocialización y educación de los menores.

2. Alternativamente a lo anterior, podrían establecerse tribunales especiales para delincuentes jóvenes-adultos de 18 a 24 años, quizá con carácter experimental en un número limitado de áreas territoriales, para lo que podría tomarse como referencia la experiencia británica Iniciativa de transición a la edad adulta (U.K. Transition to Adulthood iniciative) (puede verse en www.t2a.org.uk). Tres razones justificarían la creación de tribunales especiales para los delincuentes jóvenes adultos: 1) prevenir la administración de castigos excesivos a los jóvenes en el marco del sistema de justicia adulto con todos los inconvenientes de futuro que ello puede comportar, 2) considerar el hecho de la juventud como un factor atenuante de las sanciones y medidas aplicadas, y 3) priorizar las necesidades de desarrollo de los jóvenes por encima de otras consideraciones punitivas. En esa dirección, varios países europeos (por ejemplo, Suecia, Alemania y Austria) han tenido durante mucho tiempo un sistema diferenciado para los delincuentes de 18 a 21 años, tanto en lo relativo a las opciones de las sentencias que son aplicables a los jóvenes como a las instituciones de internamiento.

La legislación española en materia de justicia juvenil prevé múltiples medidas educativas, tanto para ser desarrolladas en la comunidad como en diversos tipos de centros. Constituye un hecho ciertamente favorable, de cara a facilitar los procesos de reinserción de los jóvenes, que los tribunales de menores apliquen preferentemente medidas de tipo comunitario (libertad vigilada, tratamiento ambulatorio, etcétera) por encima del internamiento (Redondo, Martínez, \& Andrés, en prensa). Según datos de los servicios de justicia juvenil de las distintas comunidades autónomas españolas, que ha sido recogida en un informe de Redondo et al. (en prensa), pendiente de publicación por el Ministerio de Sanidad, en España se realizan muy diversas intervenciones educativas y tratamientos con infractores juveniles, que Redondo et al. (en prensa) agruparon en siete categorías: 1) intervenciones educativas y escolares, 2) prelaborales y laborales, 3) educación psicosocial, 4) intervenciones psicoterapéuticas y tratamientos, 5) intervenciones en salud y trastornos mentales, 6) ocio y tiempo libro, y 7) intervenciones con menores y sus familias. Muchas de estas intervenciones para jóvenes hasta 18 años podrían ser fácilmente extrapolables a franjas de edad superiores, sobre la base de los razonamientos que aquí se realizan. 
Es decir, para el rango de edades jóvenes-adultos, la atención debería centrarse en la rehabilitación y no en el castigo. Dado que los menores sentenciados en los tribunales de adultos tienden a recibir sentencias más severas y a presentar mayores tasas de reincidencia que los enjuiciados por los tribunales de menores, una expectativa razonable sería que estos tribunales especiales para jóvenes-adultos también redujeran el encarcelamiento y la reincidencia, y por tanto ahorraran dinero a los contribuyentes. Además, tales tribunales deberían diseñarse de modo que produjeran menores efectos estigmatizadores que los tribunales penales para adultos.

También debería prestarse especial atención a la cuestión, a veces impopular en tiempos de frecuente invocación de políticas de "tolerancia cero", de la reaceptación adecuada de los delincuentes juveniles en la vida comunitaria (familiar, laboral, de ocio, etcétera). La condena y estigmatización de los infractores juveniles en el marco de las instituciones de justicia puede tener graves efectos perniciosos para su vida presente y sus posibilidades sociales futuras (Lemert, 197?, 1981). En un paralelismo inverso al etiquetado que acompaña a los procesos de control penal, la reinserción social de los jóvenes infractores probablemente requeriría un proceso final de "des-etiquetamiento", que formalice su vuelta a la comunidad social y reinstaure su consideración como nodelincuentes (Braithwaite, 1996, 2000; Liebling y Maruna, 2005; Maruna, LeBel, Mitchell, y Naples, 2004).

Considérese que incluso en un ámbito tan grave y sensible como el del terrorismo, tales procesos de reconciliación social y des-etiquetado final son probablemente necesarios, y algunos pasos han comenzado a darse ya España en esa dirección, en relación con el anterior terrorismo de ETA. ¿Cómo no va a ser también conveniente efectuar dichos procesos de reintegración comunitaria con los jóvenes infractores, en favor de su definitiva desistencia delictiva?

3. La mayoría de las investigaciones demuestran que ni las sentencias más largas ni los periodos de encarcelamiento más prolongados, que son mecanismos de uso habitual con los delincuentes adultos, reducen la reincidencia de los delincuentes graves. Por esta razón, aquí se sugiere una tercera vía consistente en establecer servicios especiales para delincuentes jóvenes-adultos que incluyan programas tales como terapia cognitivoconductual, tratamiento farmacológico, justicia restaurativa, tutorías, educación y formación profesional, y liberación condicional para trabajar. En Estados Unidos, 
también existen ya centros especiales para jóvenes- adultos en algunos estados (por ejemplo, en Pennsylvania).

4. Para el caso de las condenas a los delincuentes jóvenes-adultos podría establecerse una "atenuación por inmadurez". Es decir, una disminución en la severidad de las penas impuestas en función de que los jóvenes presentan una menor madurez, o una culpabilidad y responsabilidad disminuidas. En esa dirección, en Estados Unidos las penas de muerte y las cadenas perpetuas sin libertad condicional deberían abolirse como mínimo para el caso de los delincuentes jóvenes-adultos.

5. Sería conveniente efectuar evaluaciones de riesgo/necesidades de los delincuentes jóvenes-adultos para guiar la mejor elección de medidas e intervenciones apropiadas. Esta selección debería evaluar los aspectos recogidos en los epígrafes 1-9 del Recuadro 2 , además de atender a un factor de riesgo primario como es la baja inteligencia. Los delincuentes jóvenes-adultos con problemas de abuso de sustancias tendrían que ser remitidos a tribunales específicos de drogas, y aquellos otros con problemas de salud mental tratados por profesionales especializados de este campo.

6. Deberían ofrecerse programas de eficacia probada para los delincuentes jóvenesadultos directamente en la comunidad y también después de su liberación de instituciones cerradas, incluyendo asimismo terapia multisistémica, terapia cognitivoconductual, tratamiento farmacológico, justicia restaurativa, tutorías, programas de educación y formación profesional, y programas tales como el aludido Comunidades que cuidad. Para fomentar el desistimiento delictivo deberían ofrecerse programas de empleo y de mejora de la interacción social, así como otras intervenciones destinadas a reducir las transiciones vitales desordenadas y problemáticas, tales como abandonar la escuela secundaria sin graduarse, o como la paternidad adolescente. Otros programas útiles pueden ser aquellos especialmente dirigidos a barrios de alta criminalidad que se orientan a reducir las oportunidades delictivas, tales como "patrullas policiales de lugares de concentración de delitos" y prevención situacional del delito, evitación de la adscripción a bandas juveniles, y reducción del tráfico de drogas. Además, a la luz de los efectos positivos que a largo plazo tienen los programas de visitas domiciliarias (para mejorar el cuidado sanitario de los bebés en contextos familiares de riesgo), los programas de capacitación de los padres para la crianza infantil, $y$, en general, las intervenciones familiares, todos estos programas se deberían aplicar de forma más 
amplia y efectuarse seguimientos para evaluar sus efectos sobre la futura delincuencia juvenil.

Todas estas iniciativas tendrían que incluir evaluaciones sistemáticas de eficacia, a la vez que análisis costo-beneficio. Asimismo, en dichas evaluaciones debería analizarse qué incidencia tienen variables personales y sociodemográficas importantes tales como edad, sexo, o diferencias étnicas.

Desde este trabajo se insta a los gobiernos de los países desarrollados a diseñar planes de acción que atiendan las principales recomendaciones científicas de este informe, con el objetivo de que la justicia se aplique de manera más justa y atendiendo en mayor grado al conocimiento de los procesos de maduración de los jóvenes. Consideramos que las recomendaciones que aquí se realizan pueden ofrecer mayores posibilidades y esperanza de reducción de la delincuencia y de mejora de la seguridad pública, a la vez que resultar económicamente más eficientes, que no la pura aplicación de penas de prisión más largas para los jóvenes o su mera remisión a la justicia penal adulta.

\section{REFERENCIAS BIBIOGRÁFICAS}

Anderson, R. N., \& Smith, B. L. (2002). Deaths: Leading causes for 2002. National Vital Statistics Report, 53, 1-92.

Bartolomé, R., Montañés, M., Rechea, C., \& Montañés, J. (2009). Los factores de protección frente a la conducta antisocial: ¿Explican las diferencias en violencia entre chicas y chicos? Revista Española de Investigación Criminológica, 7, 3.

Bernuz, M.J., Fernández, E., \& Pérez, F. (2009a). Educar y controlar: la intervención Comunitaria en la Justicia de Menores. Revista Electrónica de Ciencia Penal y Criminología, 11-12.

Bernuz, M.J., Fernández, E., \& Pérez, F. (2009b). La libertad vigilada como medida individualizadora en la Justicia de Menores. Revista Española de Investigación Criminológica, 7, 6.

Bijleveld, C., van der Geest, V., \& Hendriks, J. (en prensa). Vulnerable youth on pathways to adulthood. En R. Loeber, M. Hoeve, N. W. Slot, \& P. van der Laan (Eds.), Persisters and desisters in crime from adolescence into adulthood: Explanation, prevention and punishment. Aldershot UK: Ashgate.

Blokland, A. A. J., \& Palmen, H. (en prensa). Criminal career patterns from adolescence to early adulthood. En R. Loeber, M. Hoeve, N. W. Slot, and P. van der Laan (Eds.), Persisters and desisters in crime from adolescence into adulthood: Explanation, prevention and punishment. Aldershot UK: Ashgate.

Blumstein, A., Cohen, J., Roth, J. A., \& Visher, C. A. (1986). Criminal careers and “career criminals." Washington, DC: National Academy Press.

Braithwaite, J. (1996). Crime, shame and reintegration. En P. Cordella y L. Siegel (Eds.), Readings in contemporary criminological theory (pp. 33-44). New York: Northeastern. 
Braithwaite, J. (2000). Shame and Criminal Justice. Canadian Journal of Criminology, 42(3), 281-298.

Bravo, A., Sierra, M.J., \& del Valle, J. (2007). Evaluación de resultados de las medidas de responsabilidad penal juvenil en Asturias. Asturias: Gobierno del Principado de Asturias.

Capdevila, M., Ferrer, M., \& Luque, E. (2006). La reincidencia en el delicte en la justicia de menors. Barcelona: Centre d'Estudis Jurídics i Formació Especializada (Colección Justicia y Sociedad, $\mathrm{n}^{\mathrm{o}} 25$ ).

Cullen, F.T., \& Gendreau, P. (2006). Evaluación de la rehabilitación correccional: política, práctica y perspectivas. En R. Barberet y J. Barquín, Justicia penal siglo XXI: Una selección de Criminal Justice 2000 (pp. 275-348). Granada: Editorial Comares.

Edwards, D. L., Schoenwald, S. K., Henggeler, S. W., \& Strother, K. B. (2001). A multilevel perspective on the implementation of Multisystemic Therapy (MST): attempting dissemination with fidelity. En G.A. Bernfeld, D.P. Farrington, \& A.W. Leschied, Offender rehabilitation in practice: Implementing and evaluating effective programs (pp. 97-120). Chichester: Wiley.

Elliott, D. S., Pampel, F., \& Huizinga, D. (2004). Youth violence: Continuity and desistance. A supplemental report to Youth Violence: A report of the Surgeon General. Boulder, CO: Center for the Study and Prevention of Violence, Institute of Behavior Science, University of Colorado.

Fabio, A., Cohen, J., \& Loeber, R. (en prensa). Neighborhood socioeconomic disadvantage and the shape of the age-crime curve. American Journal of Public Health.

Farrington, D. (2008). Integrated developmental and life-course theories of offending. New Jersey: Transaction Publishers.

Farrington, D. P. (1986). Age and crime. En M. Tonry, \& N. Morris (Eds.), Crime and justice: An annual review of research (Vol. 7, pp. 189-250). Chicago, IL: University of Chicago Press.

Farrington, D. P. (2003). Key results from the first 40 years of the Cambridge Study in Delinquent Development. En T. P. Thornberry, \& M. D. Krohn (Eds.), Taking stock of delinquency: An overview of findings from contemporary longitudinal studies (pp. 137-183). New York: Kluwer-Plenum.

Fox, J. A., \& Zawitz, M. W. (2001). Homicide trends in the United States. Washington, DC: US Bureau of Justice Statistics.

Hawkins, J. D., Brown, E. C., Oesterle, S., Arthur, M. W., Abbott, R. D., \& Catalano, R. F. (2008). Early effects of communities that care on targeted risks and initiation of delinquent behavior and substance abuse. Journal of Adolescent Health, 43, 15-22.

Henggeler, S. W., \& Borduin, C. M. (1990). Family therapy and beyond: A multisystemic approach to treating the behavior problems of children and adolescents. Pacific Grove, CA: Brooks/Cole.

Hipwell, A. E., \& Loeber, R. (2006). Do we know which interventions are effective for disruptive and delinquent girls? Clinical Child and Family Psychology Review, 9, 221-255.

Horney, J., Tolan, P., \& Weisburd, D. (2012). Contextual influences. En R. Loeber \& D. Farrington (Eds.), From Juvenile Delinquency to Adult Crime: Criminal Careers, Justice Policy and Prevention (pp. 86-117). Oxford: Oxford University Press, en prensa. 
Howell, J. C. (2011). Understanding and combating gangs in America. Thousand Oaks, CA: Sage.

Huizinga, D., Thornberry, T. P., Knight, K. E., Lovegrove, P. J., Loeber, R., Hill, K., \& Farrington, D. P. (2006). Disproportionate minority contact in the juvenile justice system: A study of differential minority arrest/referral to court in three cities. Report to the Office of Juvenile Justice and Delinquency Prevention. Access: http://www.ncjrs.gov/pdffiles1/ojjdp/grants/219743.pdf

Kershaw, C., Nicholas, S., \& Walker, A. (2008). Crime in England and Wales 2007/08. London: Home Office. www.homeoffice.gov.uk/rds/pdfs08/hosb0708.pdf.

Killias, M., Redondo, S., \& Sarnecki, J. (2012). European perspectives. En R. Loeber, \& D. Farrington (Eds.), From Juvenile Delinquency to Adult Crime: Criminal Careers, Justice Policy and Prevention (pp. 278-314). Oxford: Oxford University Press, en prensa.

Koolhof, R., Loeber, R., Wei, E. H., Pardini, D., \& Collot d'Escury, A. (2007). Inhibition deficits of serious delinquent boys of low intelligence. Criminal Behaviour and Mental Health, 17, 274-292.

Le Blanc, M., \& Fréchette, M. (1989). Male criminal activity from childhood through youth: Multilevel and developmental perspectives. New York: Springer.

Lemert, E.M. (197?). Desviación Primaria y Secundaria. En R. del Olmo, Estigmatización y conducta desviada (pp. 97-102). Maracaibo (Venezuela): Centro de Investigaciones Crimnológicas, Universidad de Zulia.

Liebling, A., \& Maruna, S. (2005). Introduction: the effects of imprisonment revisited. En A. Liebling, \& S. Maruna, The effects of imprisonment (pp. 1-29) Cullompton, Devon (Reino Unido): Willan Publishing.

Lipsey, M. W. (2009). The primary factors that characterize effective interventions with juvenile offenders: A meta-analytic overview. Victims and Offenders, 4, 124147.

Littell, J.H. (2005). A systematic review of offects of multisystemic therapy. Comunicación presentada en el 14th World Congreso of Criminology, University of Pensylvania, 8, agosto.

Loeber, R., \& Farrington, D. P. (2011). Young homicide offenders and victims: Development, risk factors and prediction from childhood. New York: Springer.

Loeber, R., Farrington, D. P., Stouthamer-Loeber, M., \& White, H. R. (2008). Violence and serious theft: Development and prediction from childhood to adulthood. Mahwah, NJ: Lawrence Erlbaum.

Luengo, M.A., Carrillo de la Peña, M.T., Otero, J.M., \& Romero, E. (1994). A Short Term Longitudinal Study of Impulsivity and Antisocial Behaviour. Journal of Personality and Social Psychology, 66, 3, 542-548.

Martín Solbes, V. (2008). Estudio socioeducativo de los jóvenes internados en las prisiones andaluzas. Revista Española de Investigación Criminológica, Artículo 3, Número 6 (www.criminologia.net).

Maruna, S., LeBel, T., Mitchell, N., \& Naples, M. (2004). Pygmalion in the reintegration process: desistence from crime through the looling glass. Psychology, Crime \& Law, 10(3), 271-281.

Moffitt, T. (1993). Adolescence-limited and life-course-persistent antisocial behavior: A developmental taxonomy. Psychological Review, 100(4), 674-701.

Ortega, E., García, J. \& De la Fuente, L (2009). Estudio meta-analítico de la reincidencia de los menores infractores en España. XI Congreso de Metodología de las Ciencias Sociales y de la Salud, Málaga, España. 
García, J., Ortega, E., \& De la Fuente, L. (2010). Juvenile offenders recidivism in Spain. A quantitative revision. En Verdugo \& M. Frias (Ed.), Bio-Psycho-Social Perspectives on Interpersonal Violence (pp. 333 - 353). NewYork: Nova Science Publishers.

Piquero, A. R., Farrington, D. P., \& Blumstein, A. (2007). Key issues in criminal career research: New analyses of the Cambridge Study in Delinquent Development. Cambridge, UK: Cambridge University Press.

Piquero, A., Hawkins, D., \& Kazemian, L. (2012). Criminal career patters. En R. Loeber, \& D. Farrington (Eds.), From Juvenile Delinquency to Adult Crime: Criminal Careers, Justice Policy and Prevention (pp. 14-46). Oxford: Oxford University Press, en prensa.

Piquero, A.R., Jennings, W., \& Farrington, D. P. (2010). On the malleability of selfcontrol: Theoretical and policy implications regarding a general theory of crime. Justice Quarterly, 27, 803-834.

Rechea, C. (2008). Conductas antisociales y delictivas de los jóvenes de España. Informe para el Consejo del Poder Judicial (http://www.uclm.es/Criminologia/pdf/16_2008.pdf).

Redondo, S. (2008). Individuos, sociedades y oportunidades en la explicación y prevención del delito: Modelo del Triple Riesgo Delictivo (TRD). Revista Española de Investigación Criminológica, Artículo 7, N. 6. (Accesible en: www.criminologia.net).

Redondo, S., Funes, J., \& Luque, E. (1994). Justicia penal y reincidencia. Barcelona: Fundació Jaume Callís.

Redondo, S., Martínez, A., \& Andrés, A. (en prensa). Factores de éxito asociados a los progamas de intervención con menores. Informes, Estudios e Investigaciones, Ministerio de Sanidad, Política Social e Iguadad.

Romero, E. (2006). Prevención temprana del abuso de drogas: Estudio de segumiento e intervención multicomponente. Justificación de proyecto de investigación en drogodependencias. Departamento de Clínica y Psicobiología, Facultad de Psicologia, Universidad de Santiago de Compostela.

Rosenfeld, R., White, H., Esbensen, F.-A. (2012). Special categories of serious and violent offenders: Drug dealers, gang members, homicide offenders, and sex offenders. En R. Loeber, \& D. Farrington (Eds.), From Juvenile Delinquency to Adult Crime: Criminal Careers, Justice Policy and Prevention (pp. 14-46). Oxford: Oxford University Press, en prensa.

San Juan, C., \& Ocáriz, E. (2009). Evaluación de la intervención educativa y análisis de la reincidencia en la Justicia de Menores en la CAPV. Vitoria-Gasteiz: Servicio Central de Publicaciones del Gobierno Vasco.

San Juan, C., Ocáriz, E., \& de la Cuesta, J.L. (2007). Evaluación de las medidas en medio abierto del plan de justicia juvenil de la comunidad autónoma del País Vasco. Boletín Criminológico, 96.

Schaeffer, C. M., \& Borduin, C. M. (2005). Long-term follow-up to a randomized clinical trial of multisystemic therapy with serious and violent juvenile offenders. Journal of Consulting and Clinical Psychology, 73, 445-453.

Schoenwald, S. K., Heiblum, N., Saldana, L., \& Henggeler, S. W. (2008). The international implementation of multisystemic therapy. Evaluation \& the Health Professions, 31(2), 211-225. 
Sobral, J., Romero, E., Luengo, A., \& Marzoa, J. (2000). Personalidad y conducta antisocial: amplificadores individuales de los efectos contextuales. Psicothema, 12(4), $661-670$

Stouthamer-Loeber, M. (2010). Persistence and desistance in offending. Unpublished report. Life History Research Program, University of Pittsburgh, Pittsburgh, PA.

Stouthamer-Loeber, M., Loeber, R., Stallings, R., \& Lacourse, E. (2008). Desistance from and persistence in offending. En R. Loeber, D. P. Farrington, M. Stouthamer-Loeber, \& H. R. White, Violence and serious theft: Risk and promotive factors from childhood to early adulthood (pp. 269-308). Mahwah, NJ: Erlbaum.

Truman, J. L., \& Rand, M. R. (2010). Crime victimization, 2008 (NCJ 231327). Washington, DC: US Department of Justice.

Welsh, B., Lipsey, M., Rivara, F., Hawkins, J., Aos, S., \& Hollis-Peel, M. (2012). Promoting change, changing lives: Effective prevention and intervention to reduce serious offending. En R. Loeber, \& D. Farrington (Eds.), From Juvenile Delinquency to Adult Crime: Criminal Careers, Justice Policy and Prevention (pp. 14-46). Oxford: Oxford University Press, en prensa.

Zahn, M. A., Day, J. C., Mihalic, S. F., \& Tichavsky, L. (2009). Determining what works for girls in the juvenile justice system. Crime and Delinquency, 55, 266293.

Zara, G., \& Farrington, D. P. (2009). Childhood and adolescent predictors of late onset criminal careers. Journal of Youth and Adolescence, 38, 287-300.

Zara, G., \& Farrington, D. P. (2010). A longitudinal analysis of early risk factors for adult-onset offending: What predicts a delayed criminal career. Criminal Behaviour and Mental Health, 20, 257-273. 